Article

\title{
Hepatoprotective and Renoprotective Properties of Lovastatin-Loaded Ginger and Garlic Oil Nanoemulsomes: Insights into Serum Biological Parameters
}

\author{
Syed Ali Faran ${ }^{1}$, Sajid Asghar ${ }^{1, *}{ }^{\circledR}$, Syed Haroon Khalid ${ }^{1}$, Ikram Ullah Khan ${ }^{1}(0$, \\ Muhammad Asif ${ }^{1}$, Ikrima Khalid ${ }^{1}$, Umar Farooq Gohar ${ }^{2}$ and Tanveer Hussain ${ }^{3, *}$ \\ 1 Faculty of Pharmaceutical Sciences, Government College University Faisalabad, Faisalabad 38000, Pakistan \\ 2 Institute of Industrial Biotechnology, Government College University Lahore, Lahore 54000, Pakistan \\ 3 Faculty of Engineering and Technology, National Textile University, Faisalabad 38000, Pakistan \\ * Correspondence: sajidasghar@gcuf.edu.pk (S.A.); tanveer@ntu.edu.pk (T.H.)
}

Received: 30 June 2019; Accepted: 3 September 2019; Published: 9 September 2019

\begin{abstract}
Background and Objectives: Dyslipidemia is gaining much attention among healthcare professionals because of its high association with the malfunctioning of a number of normal physiological and metabolic processes in the body. Obesity is directly interconnected with dyslipidemia and is said to be a denouement of hyperlipidemia and, if left untreated, may lead to intense damage to organs that are directly involved in fat metabolism. The objective of this study was to investigate the synergistic antiobesity and anti-hyperlipidemic activities along with hepato- and renoprotective potential of nanoemulsomes (NES) of lovastatin (LTN)-loaded ginger (GR) and garlic (GL) oils. Materials and Methods: LTN nanoemulsomes co-encapsulated with GR oil and GL oil were prepared by a thin hydration technique. Eight-week-old male Wistar rats weighing 200-250 g were induced with hyperlipidemia via a high-fat diet (HFD) comprising $40 \%$ beef tallow. Body weight, serum biochemical lipid parameters, and those for liver and kidney functions, serum TC, LDL-C, vLDL-C, HDL-C, TG, atherogenic index (AI), ALT, AFT, ALP, $\gamma$-GT, total protein (TP), serum albumin and globulin ratio $(\mathrm{A} / \mathrm{G})$, serum creatinine, blood urea nitrogen $(\mathrm{BUN})$ and blood urea, and histopathology of hematoxylin and eosin (H\&E) stained liver and kidney sections of all aforementioned groups were examined in the treated animals. Results: Nanoemulsomes of LTN-loaded GR and GL oils provided synergistic effects with LTN, exerted better ameliorative actions in reducing serum TC, LDL-C, vLDL-C, triglycerides, and AI, and improved serum HDL-C levels. Serum ALT, AST, ALP, and $\gamma$-GT levels were in the normal range for nanoemulsome groups. H\&E stained liver and kidney sections of these animals confirmed better hepatoprotective and renoprotective effects than LTN alone. Serum biochemical parameters for renal functions also claimed to be in the moderate range for nanoemulsome-treated groups. Conclusion: This study demonstrated that nanoemulsomes of LTN-loaded GR and GL oils synergistically provided better antihyperlipidemic, hepatoprotective, and renoprotective effects as compared to LTN alone.
\end{abstract}

Keywords: lovastatin; anti-hyperlipidemia; hepatoprotective; renoprotective; ginger oil; garlic oil; nanoemulsomes

\section{Introduction}

Dyslipidemia is known to be a metabolic disorder of lipid metabolism that distends as a result of inappropriate lipid metabolism (lipogenesis and lipolysis), ultimately leading to obesity and other diseases [1]. Obesity, in the modern world, is dramatically challenging our confidence, originating from 
the drastically changing lifestyle of the general population [2]. Obesity, along with hyperlipidemia and hypertension, is considered to be highly interconnected with the swift instigation of nonalcoholic fatty liver disease (NAFLD) [3]. NAFLD prevails more in obese patients than nonobese ones. Its prevalence is up to $30 \%-60 \%$ in obese adults, and about $20 \%-25 \%$ of this population is prone to nonalcoholic steatohepatitis (NASH) or may also develop end-stage hepatic cancer if left untreated [4]. NAFLD is considered to occur from the upregulation of enzymes including HMG Co-A reductase, sterol regulatory element-binding protein-1c (SREBP1-c), and acetyl coenzyme A carboxylase (ACC), which are directly involved in cholesterol synthesis. These enzymes are triggered upon excess deposition of saturated and free fatty acids (FFA) in adipocytes, owing to intake of a fat-rich diet [5].

The relationship between renal injury and excessive lipid intake was found one and a half centuries ago by Virchow in 1858, who claimed that renal epithelium fatty degeneration occurred in Bright's disease [6]. Later, a number of investigators discovered that epithelial cell injury and mesangial proliferation caused by lipids have direct roles in the progression of renal diseases [7]. High fat intake has direct involvement in the advent of cardiovascular, hepatic, and renal abnormalities. Moreover, dyslipidemia and/or hyperlipidemia induced by a high-fat diet are known to aggressively affect the normal physiology of kidneys. Among various hyperlipidemia-induced renal abnormalities, glomerulosclerosis and lipid-induced oxidative stress are two major problems that ultimately lead to altered or abnormal functioning of nephrons, and they may progress to kidney failure or renal impairment if left untreated [8-10]. Podocyte injury and mesangial sclerosis are highly associated with elevated levels of plasma cholesterol and triglycerides [11]. High-density lipoprotein cholesterol (HDL-C) and low-density lipoprotein cholesterol (LDL-C) generate high oxidative stress in renal injury, and this leads to lower lipoprotein production and worsens renal injury [6].

Hepatic and renal injuries, induced by excess lipid deposition in the body, can be reversed by a number of mechanisms and by using a number of naturally occurring therapeutic agents. Ginger (GR) and garlic (GL) are endowed with a long list of therapeutically active compounds that have shown promising results in compensating such aforementioned abnormalities [12,13]. GR contains various potent chemical constituents that are known to produce beneficial effects in normalizing a number of physiological functions [14]. GR, owing to its rich phytochemical history, has been shown to ameliorate total lipid profile of animals by imparting hepatoprotective and renoprotective effects in obesity-induced hyperlipidemic conditions in rat models [15-18].

Like GR, GL is also known for its remediation properties against fat-induced hepatic and renal injuries. GL contains a large proportion of organosulfur compounds such as allicin, S-allaylcystein, allyl sulfide, diallayl sulfide (DAS), and diallyl disulfide (DADS), which play pivotal roles in managing lipid-induced morphological changes to key organs. These compounds are proven to have antioxidant [19] and antihyperlipidemic [20] activities along with a specificity to provide renoprotective [21] and hepatoprotective effects [22].

Statins have been widely described as direct lipid-lowering agents. Besides this remarkable action, they have also been reported to exert protective actions to organs directly affected by the accumulation of fatty acids [23-25]. Lovastatin (LTN), a potent prodrug of the statin family, is the fermented product of red yeast rice [26]. The metabolic product of LTN tends to inhibit a rate-limiting enzyme, 3-hydroxy-3-methyl glutaryl coenzyme A (HMG Co-A) reductase, involved in the biosynthetic and metabolic pathways of cholesterol [27]. LTN has a direct role in lowering total cholesterol (TC) and LDL-C, hence preventing risks of coronary heart diseases [28]. Besides providing lipid-alleviating and hepatoprotective effects, LTN has also been widely reported to directly deliver renoprotective effects when the organ is majorly damaged due to high fat deposition [29].

All these aforementioned agents have been used alone or in combination with other xenobiotics. In this study, the antihyperlipidemic capacities of drug-loaded GR (Moon scientific traders, Punjab, Pakistan) and GL oil- nanoemulsomes (Moon scientific traders, Punjab, Pakistan) were measured with an emphasis on evaluating the synergistic effects of the active drug and oils on lipid metabolism. 
Serum biochemical analyses of various biomarkers of hepatic and renal functions were performed to establish the efficacy of drug-loaded GR and GL oil- nanoemulsomes.

\section{Materials and Methods}

LTN was obtained as a kind gift from Nabiqasim Industries, Pakistan. Stearic acid was cordially gifted by Saffron Pharmaceuticals Pvt. Ltd. Punjab, Pakistan. GR and GL oils were procured from Moon scientific traders, Punjab, Pakistan. Phospholipon 90G (lecithin stabilized with $0.1 \%$ ascorbyl palmitate) was a kind present from Lipoid AG, Steinhausen, Switzerland. Ethanol, chloroform, formaldehyde, and glycerol were procured from Musaji Adam \& Sons, Karachi, Pakistan. All other solvents, chemicals, and reagents used were of analytical grade.

\subsection{Preparation of Lipid Nanoformulations}

Lipoidal nanovesicular systems (nanoemulsomes) were fabricated by the thin layer hydration technique with slight modifications [30]. Firstly, the lipid phase $(0.1 \mathrm{~g})$ was formed in $10 \mathrm{~mL}$ of an ethanol/chloroform (1:1 v/v) mixture at a 1:2 ratio of solid lipid to liquid lipid for both GR and GL oils, separately. Fixed amounts of drug and phospholipon $90 \mathrm{G}$ (stabilizer) were added to lipid mixture (Table 1). The mixture of lipids was then dried in a rotary evaporator (RE-100 Pro, D-Lab, USA) maintained at $40{ }^{\circ} \mathrm{C}$ and $60 \mathrm{rpm}$, leaving behind a thin layer of residues on the walls of a round-bottom flask. This layer was hydrated in parts with $20 \mathrm{~mL}$ of a $10 \% \mathrm{v} / \mathrm{v}$ glycerol solution with continuous shaking for 15-20 min. Finally, this pre-emulsion was subjected to sonication using a probe-type ultrasonicator (3000 MP, BioLogics, Inc, Manassas, VA, USA) at $150 \mathrm{~W}$ for $5 \mathrm{~min}$ to yield nanoemulsomes. These formed nanoemulsomes were then stored at $4{ }^{\circ} \mathrm{C}$ until utilization.

Table 1. Composition of lovastatin (LTN)-loaded nanoemulsomes prepared by thin layer hydration.

\begin{tabular}{cccccc}
\hline $\begin{array}{c}\text { Formulation } \\
\text { Code }\end{array}$ & $\begin{array}{c}\text { Stearic Acid } \\
(\mathbf{m g})\end{array}$ & $\begin{array}{c}\text { Garlic (GL) } \\
\text { Oil } \mathbf{( m g )}\end{array}$ & $\begin{array}{c}\text { Ginger (GR) } \\
\text { Oil (mg) }\end{array}$ & $\begin{array}{c}\text { Phospholipon } \\
\text { 90G (mg) }\end{array}$ & LTN (mg) \\
\hline NES-GL 1:2 & 27 & 53 & - & 330 & 20 \\
NES-GR 1:2 & 27 & - & 53 & 330 & 20 \\
\hline
\end{tabular}

\subsection{Particle Size, Zeta Potential, and Polydispersity Index (PDI)}

Particle size, zeta potential, and the polydispersity index (PDI) of nanoformulation suspensions diluted in double-distilled water were evaluated by dynamic light scattering (DLS) using Malvern Nano ZS90, UK. Results were obtained in triplicate, and their averages were taken.

\subsection{Experimental Animals}

Thirty male Wistar rats (8 weeks old) weighing 200-250 g were used in this hypercholesterolemic rat model. These rats were obtained from the Animal Laboratory, Faculty of Pharmaceutical Sciences, Government College University Faisalabad, Pakistan. All animals were kept in a well cleaned and ventilated animal room at a controlled room temperature of $25 \pm 2{ }^{\circ} \mathrm{C}$ with a humidity level of $65 \% \pm 5 \%$ over $12 \mathrm{~h}$ dark/light cycles with free access to basal diet and water ad libitum. Rats were acclimatized in this environment for one week before commencement of the experiment. Animal experimentation was carried out as per institutional and international guidelines for animal care and ethics and was approved by the Institutional Review Board, Government College University Faisalabad (Ref No. GCUF/ERC/2010, Study No. 19610, IRB No. 610, Dated 25 March 2019). 


\subsection{Experiment Protocol}

Initially, for a period of 4 weeks, rats were divided into 2 groups: group I or group A $(n=6)$ was fed a normal control diet or basal diet, and group II $(n=24)$ was fed a high-fat diet containing $40 \%$ beef tallow [31]. At the beginning of the 5th week (initiation of treatment period), rats from group II were further randomly divided into 4 groups each comprising 6 rats $(n=6)$ and given treatments described below until the end of the 8 th week.

Groupe A: Rats were given a normal control diet over a continuous period of 8 weeks.

Groupe B: Rats were fed only a high-fat diet and termed as the high-fat diet (HFD) group.

Groupe C: Rats were given pure LTN (dose $=30 \mathrm{mg} / \mathrm{kg} / \mathrm{d}$ ), suspended in $1.8 \%$ carboxymethyl cellulose (CMC) solution with concomitant administration of HFD.

Groupe D: Rats were kept on HFD along with administration of GR oil nanoemulsomes at an equivalent dose of $30 \mathrm{mg} / \mathrm{kg} / \mathrm{d}$.

Groupe E: Rats were kept on HFD along with administration of GL oil nanoemulsomes at an equivalent dose of $30 \mathrm{mg} / \mathrm{kg} / \mathrm{d}$.

During this period of 8 weeks, weights of all animals were noted on weekly basis to evaluate the effects of treatments on body weight as well. Antihyperlipidemic treatment was started at the end of the 4 th study week and continued until the end of the 8 th week of study.

\subsection{Serum Biochemical Analyses for Evaluation of the Lipid Profile}

Blood samples were taken from sacrificed animals in glass vacutainers and were immediately subjected to centrifugation at $6000 \mathrm{rpm}$ for $15 \mathrm{~min}$. The supernatant serum layer was then separated from each tube and was carefully stored at $-20^{\circ} \mathrm{C}$ until further analyses. Total cholesterol (TC), triglycerides (TG), low-density lipoproteins (LDL-C), very low density lipoproteins (vLDL-C), and high-density lipoproteins (HDL-C) were measured using commercially available diagnostic kits (Crescent diagnostics, Jeddah, Saudi Arabia) adopting the calorimetric method (CLARIOstar ${ }^{\circledR}$, BMG LABTECH, SpectraMax ${ }^{\circledR}$ M5e Microplate Reader). Atherosclerosis risk factor was calculated by computing atherogenic indices (AI) as per the following formula given in literature [32]. Furthermore, the TG/HDL-C ratio was investigated to calculate insulin resistance as reported elsewhere [33].

$$
A I=\frac{L D L+v L D L}{H D L}
$$

\subsection{Serum Biochemical Analyses for Evaluation of the Liver Function Tests (LFTs)}

Serum analyses for various biomarkers of LFTs were done using commercial kits (Crescent diagnostics, Jeddah). These biomarkers include alanine aminotransferase (ALT), aspartate aminotransferase (AST), gamma glutamyl transpeptidase $(\gamma-\mathrm{GT})$, and alkaline phosphatase (ALP). Results were obtained following the colorimetric method. Data values were presented in international units per litter (IU/L).

\subsection{Serum Biochemical Analyses for Evaluation of the Renal Function Tests (RFTs)}

Various renal biomarkers such as serum levels of urea, creatinine, BUN, total protein, albumin, globulin, and the albumin/globulin ratio (A/G) were thoroughly examined to assess functioning of the kidneys in the presence of HFD and to evaluate the effect of GR and GL oils in synergy with LTN [34,35]. These results were presented as $\mathrm{mg} / \mathrm{dL}$ or $\mathrm{g} / \mathrm{dL}$. 


\subsection{Histopathological Examination}

Liver and kidneys from experimental animals were excised and were fixed in 10\% buffered formalin solution. Later, fixed organs were embedded in paraffin, and sections of $5 \mu \mathrm{m}$ thickness were prepared from each organ sample using a microtome. Later, tissue sections were stained with hematoxylin and eosin (H\&E) and examined microscopically (ACCU-SCOPE 3000, Commack, NY, USA) for any pathological changes induced by a high-fat diet under supervision of pathologist, and images were captured via CaptaVision software (ACCU-SCOPE, Commack, NY, USA).

\subsection{Statistical Analysis:}

Data obtained were presented as mean \pm SD. All data were subjected to one-way ANOVA with a post hoc Tukey test for multiple column comparisons using Graphpad Prism software. A $p$ value less than 0.05 was considered significant.

\section{Results}

\subsection{Preparation and Characterization of Nanoemulsomes}

Both GR and GL oil- formulations formed by thin layer hydration showed uniform and homogeneous particles with average particle sizes of 240 and $120 \mathrm{~nm}$ (Table 2), respectively. These formulations indicated good stability, as their average zeta potential values were -24 and $-20 \mathrm{mV}$, respectively. Particles in both dispersions displayed uniformity, as their PDI values were below 0.3. GL oil formulations were monodisperse and presented a much smaller size than the GR oil counterpart. The size of the formulation could play an important role in the performance of the nanopreparations.

Table 2. Particle size, zeta potential, and polydispersity index (PDI) of formed nanoemulsomes.

\begin{tabular}{cccc}
\hline Formulation Code & Particle Size $(\mathbf{n m})$ & Zeta Potential (mV) & PDI \\
\hline Garlic Nanoemulsome (NES-GL) 1:2 & $240 \pm 5.5$ & $-24 \pm 2.4$ & $0.25 \pm 0.08$ \\
Ginger Nanoemulsome (NES-GR) 1:2 & $120 \pm 4.2$ & $-20 \pm 4.8$ & $0.126 \pm 0.06$ \\
\hline
\end{tabular}

\subsection{Body Weight of Animals}

Since animals in the normal control group (group A) were kept on a normal diet, they did not achieve any significant gain $(p>0.05)$ in their body weights throughout the experiment. From Figure 1, it can be clearly seen that percent body weight of all animals of the HFD group (groups B-E) significantly increased as compared to normal control group A over the first 4 weeks. By 4 weeks, animals from groups B-E achieved marked increases in their body weights at 138.9\%, 125.6\%, 130.9\%, and $131.4 \%$, respectively. Whereas, groups $\mathrm{D}$ and $\mathrm{E}$ displayed a slight loss in weight from the 5 th to 8th week (treatment period). These results were better than group C (group treated with pure LTN suspension), which showed a slightly uplifted weight curve during the treatment period. After the 6th week, the percent weight of group D further decreased, while that of group E achieved a sustained level. At the completion of 8 weeks, the total body weight of animals of group B increased up to $200 \%$, while that of group C increased $146 \%$. Groups D and E showed a slight decline (i.e., $7 \%$ and 3\%, respectively) as compared to the weight percent of the initial 4 weeks. 


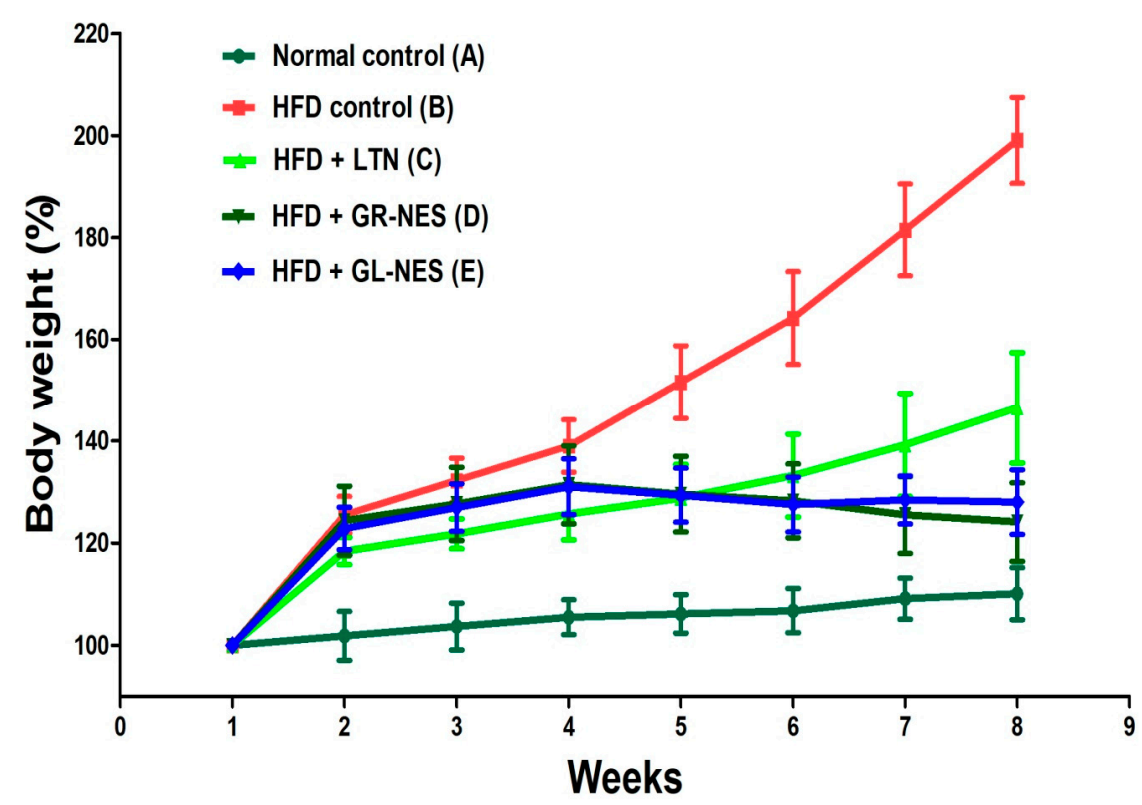

Figure 1. Percent body weight change of hyperlipidemic rat models $(n=6)$ for nanoformulations and pure LTN after 4 weeks of oral administration (dose $=30 \mathrm{mg} / \mathrm{kg} / \mathrm{d}$ ). HFD, high-fat diet.

\subsection{Lipid Profile}

\subsubsection{Total Cholesterol (TC)}

The TC level of group B significantly increased $(p<0.05)$ by $175 \%(280 \pm 11.68 \mathrm{mg} / \mathrm{dL})$ over a period of 8 weeks as compared to that of group A $(160 \pm 7.23 \mathrm{mg} / \mathrm{dL}$; Figure $2 \mathrm{~A})$. Whereas, in comparison to group A, TC levels of rats of groups C-E were $115 \%(184 \pm 7.19 \mathrm{mg} / \mathrm{dL}), 73 \%(117 \pm 9.24 \mathrm{mg} / \mathrm{dL})$, and $82 \%(131 \pm 7.4 \mathrm{mg} / \mathrm{dL})$, respectively. While amongst treated groups, there was a decrease of $37 \%$ and $29 \%$ in serum TC levels of groups D and E, respectively, as compared to that of the pure LTN-treated group $(p<0.05)$. This shows substantial lowering of serum TC levels in groups of drug-loaded nanoemulsomes.

\subsubsection{Triglycerides (TG)}

The TG level of the high-fat diet group B over a period of 8 weeks was the highest at $192 \pm 7.4 \mathrm{mg} / \mathrm{dL}$ ( $231 \%$ more than that of normal control group A). The group treated with LTN suspension in $1.8 \%$ CMC solution showed a $25 \%(144 \pm 4.34 \mathrm{mg} / \mathrm{dL})$ lower TG level as compared to group B (Figure 2B). While groups D and E displayed significant reductions $(p<0.05)$ in TG levels as compared to group B (i.e., $77.5 \pm 4.84 \mathrm{mg} / \mathrm{dL}(40 \%$ lower than group B) and $81 \pm 6.16$ (42\% lower than group B), respectively). When comparing percentage increase or decrease in TG levels of all treated animals with that of the normal control diet group A, groups D and E showed significant reductions $(p<0.05)$ of $3.4 \%$ and $8.2 \%$ reduced TG levels, respectively.

\subsubsection{Low-Density Lipoprotein Cholesterol (LDL-C)}

After the experiment was terminated, HFD control group B showed a 231\% $(210 \pm 6.95 \mathrm{mg} / \mathrm{dL})$ increase in LDL-C level against normal control group A $(90.6 \pm 9.02 \mathrm{mg} / \mathrm{dL})$. Groups D and E showed significantly $(p<0.05)$ reduced LDL-C levels: $71.8 \pm 7.21 \mathrm{mg} / \mathrm{dL}(29 \%$ lower than group A) and $86.5 \pm 7.88 \mathrm{mg} / \mathrm{dL}$ ( $5.1 \%$ lower than group A). Pure LTN suspension in CMC solution did not significantly reduce LDL-C levels $(163.9 \pm 6.64 \mathrm{mg} / \mathrm{dL})$ when compared with those of control diet group A $(p>0.05)$. Instead, it showed a higher LDL-C level when compared to groups treated with GR and GL oil (Figure 2C) drug-loaded lipid nanoformulations $(p<0.05)$. 

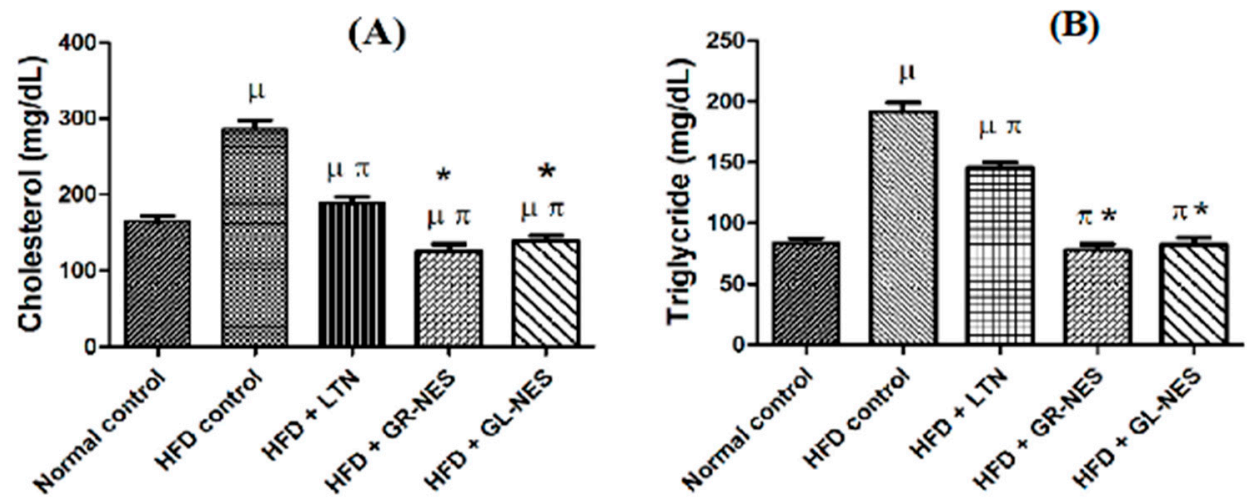

(C)
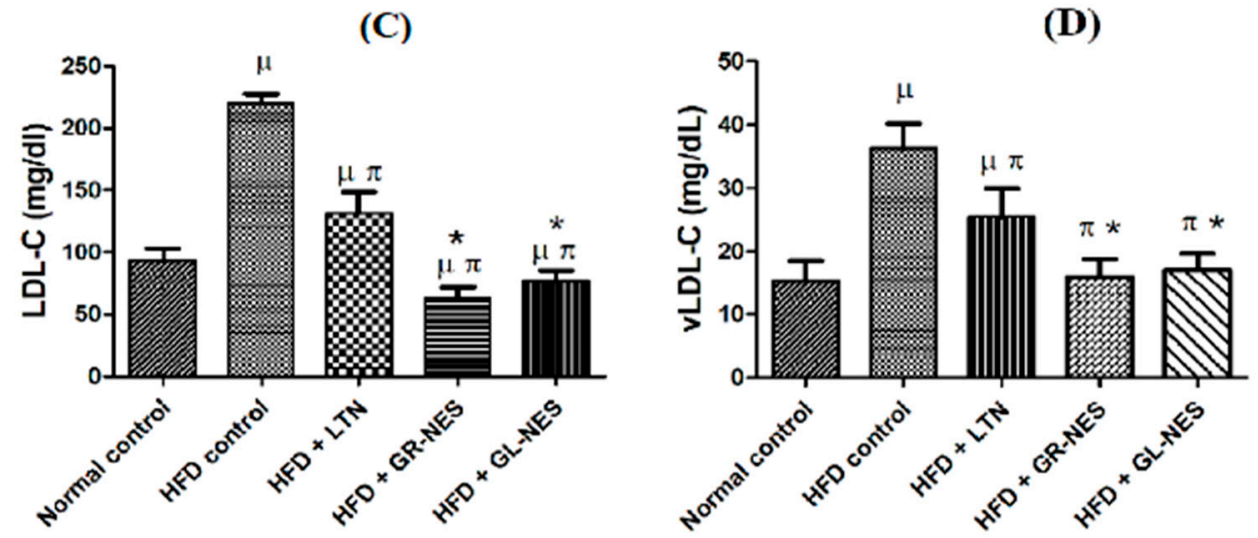

Figure 2. (A) Serum total cholesterol (TC); (B) Serum triglycerides (TG); (C) Serum low-density lipoprotein cholesterol (LDL-C); (D) Serum very low density lipoprotein cholesterol (vLDL-C) of nanoformulations and pure LTN in hyperlipidemic rat models $(n=6)$ after 4 weeks of oral administration $($ dose $=30 \mathrm{mg} / \mathrm{kg} / \mathrm{d}) . \mu$ indicates $p<0.05$ vs. normal control; $\pi$ indicates $p<0.05$ vs. HFD control; * indicates $p<0.05$ vs. HFD + LTN.

\subsubsection{Very Low Density Lipoprotein Cholesterol (vLDL-C)}

vLDL-C levels of all groups were compared with those of normal diet group A (Figure 2D). Drug-loaded GR and GL oil nanoemulsomes ameliorated the vLDL-C profile of rats in a better way as compared to pure LTN CMC suspension (group C). vLDL-C levels for these groups were $15.4 \pm 2.84 \mathrm{mg} / \mathrm{dL}(53 \%$ lower than group C) and $16.2 \pm 2.7 \mathrm{mg} / \mathrm{dL}(56 \%$ lower than group C), respectively. In comparison to the normal diet group whose vLDL-C level was $16.6 \pm 3.07 \mathrm{mg} / \mathrm{dL}$, there were respective 3\% and $8 \%$ decreases in vLDL-C levels of groups administered with GR and GL oil nanoformulations. The pure LTN suspended solution showed $28.8 \pm 4.54 \mathrm{mg} / \mathrm{dL}$ vLDL-C levels, which was $173 \%$ greater than those of normal control group A.

\subsubsection{High-Density Lipoprotein Cholesterol (HDL-C)}

Normal control group A showed $52.8 \pm 4.72 \mathrm{mg} / \mathrm{dL}$ of HDL-C after completion of the animal experiment. Groups D and $\mathrm{E}$ showed quite satisfactory results in improving HDL-C levels of rats (Figure 3A). There was no significant difference $(p>0.05)$ between HDL-C levels of these groups and normal control group A: HDL-C levels were $49.8 \pm 7.17 \mathrm{mg} / \mathrm{dL}(6 \%$ of group A) and $52.3 \pm 4.62 \mathrm{mg} / \mathrm{dL}$ $(1 \%$ of group A), respectively. HFD control group B showed a significant reduction $(p<0.05)$ in HDL-C levels (i.e., $58 \%$ ( $31 \pm 5.51 \mathrm{mg} / \mathrm{dL})$ lower than group A). The HDL-C level of rats treated with pure LTN suspension was $41.3 \pm 6.13 \mathrm{mg} / \mathrm{dL}$. This illustrates respective $17 \%$ and $21 \%$ lower levels than those of group D and E, indicating that nanoformulations administered to these groups improved HDL-C levels in a better way as compared to the simple LTN suspension. 

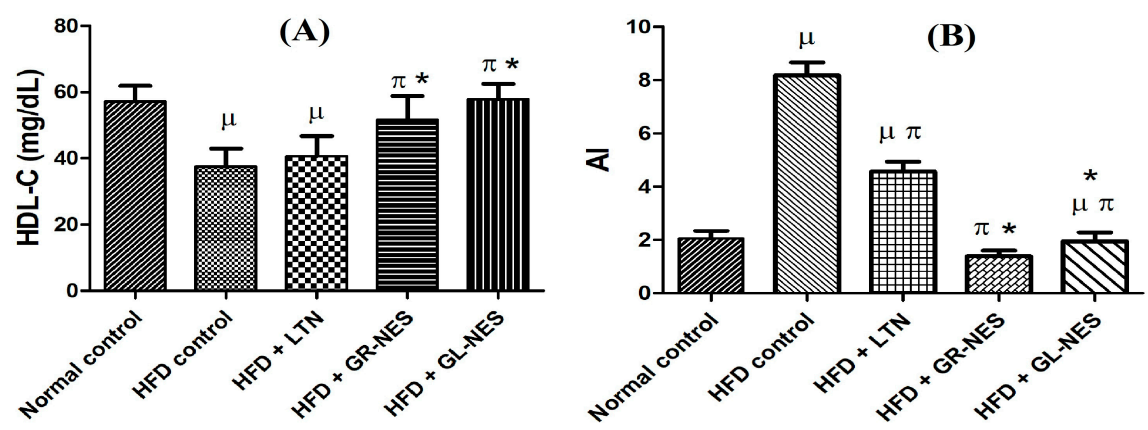

(C)

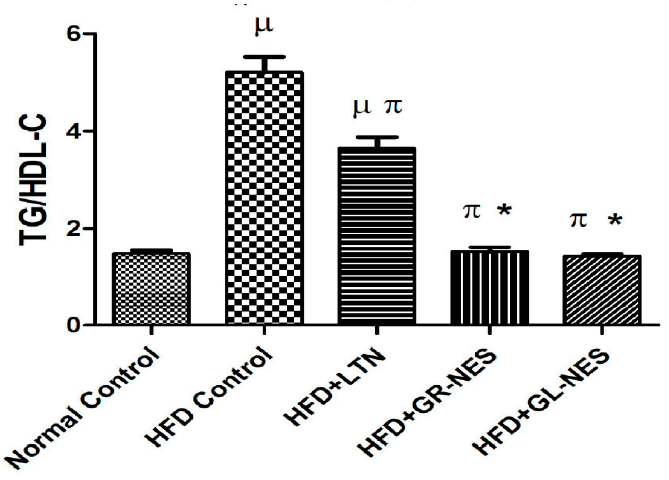

Figure 3. (A) Serum high-density lipoprotein cholesterol (HDL-C); (B) atherogenic index (AI); (C) TG/HDL-C to indicate insulin resistance of nanoformulations and pure LTN in hyperlipidemic rat models $(n=6)$ after 4 weeks of oral administration (dose $=30 \mathrm{mg} / \mathrm{kg} / \mathrm{d}$ ). $\mu$ indicates $p<0.05 \mathrm{vs}$. normal control; $\pi$ indicates $p<0.05$ vs. HFD control; * indicates $p<0.05$ vs. HFD + LTN.

\subsubsection{Atherogenic Index (AI) and Insulin Resistance}

Atherosclerosis occurrence was the lowest among animals treated with LTN nanoemulsomes. Results were compared with AI of control group A, and there was no significant difference $(p>0.05)$ between groups A and $\mathrm{E}$ regarding AI, while groups $\mathrm{A}$ and $\mathrm{D}$ were significantly different $(p<0.05)$. On the other hand, hyperlipidemic rats (group B) and those treated with pure LTN suspension (group C) showed significant differences against group A. Similarly, both groups D and E showed significant reduction in AI as compared to group $C(p<0.05)$ and further decreased the risk of atherosclerosis (Figure 3B). These results illustrate that GR and GL oil nanoemulsomes helped to combat lipid-induced fatalities by improving the lipid profile even after concomitant intake of a fat-rich diet.

The TG to HDL-C ratio (TG/HDL-C) has been suggested as a surrogate marker for detection of insulin resistance [33]. A TG:HDL-C ratio of $\geq 3$ has been shown to be closely correlated to insulin resistance. In the clinical scenario, the TG/HDL ratio has been proven to have a high correlation with the prevalence of metabolic syndrome with insulin resistance [36]. Figure 3C shows the TG/HDL to indicate insulin resistance in the animals of treatment groups. The HFD group developed the worst insulin resistance, as the TG/HDL-C ratio was greater than 5 . LTN treatment alone was not sufficient to avoid insulin resistance in the rats, as the TG/HDL-C ratio was around 3.5. Nonetheless, GR-NES and GL-NES were able to reverse insulin resistance in the rats. The TG/HDL-C ratios of normal rats and nanoemulsome-treated rats were quite similar $(p>0.05)$, and the values did not exceed 1.6.

\subsection{Liver Function Analyses (LFTs)}

\subsubsection{Alanine Aminotransferase (ALT or SGPT)}

Group B kept on a high-fat diet appeared to have a drastic increase $(277 \%)$ in plasma ALT $(168 \pm 18.69 \mathrm{IU} / \mathrm{L})$, which was significantly greater $(p<0.05)$ than that of normal control group A 
$(60.7 \pm 14.76 \mathrm{IU} / \mathrm{L} ;$ Figure $4 \mathrm{~A})$. The group treated with pure LTN suspension showed a $50 \%$ reduction $(p<0.05)$ in plasma ALT levels $(84 \pm 9.77 \mathrm{IU} / \mathrm{L})$ as compared to those of group $\mathrm{B}$, but these results were comparatively higher (i.e., $28 \%$ and 38\% higher) than ALT levels of group D (60.7 \pm 10.1 IU/L) and group E $(52.9 \pm 9.38 \mathrm{IU} / \mathrm{L})$, respectively. Animals treated in groups D and E showed significantly reduced ALT levels $(p<0.05)$ in comparison to those of group $\mathrm{B}$, indicating that animals of these groups recovered from NAFLD in a better way as compared to the other groups. These results are in accordance with a previous study [37].
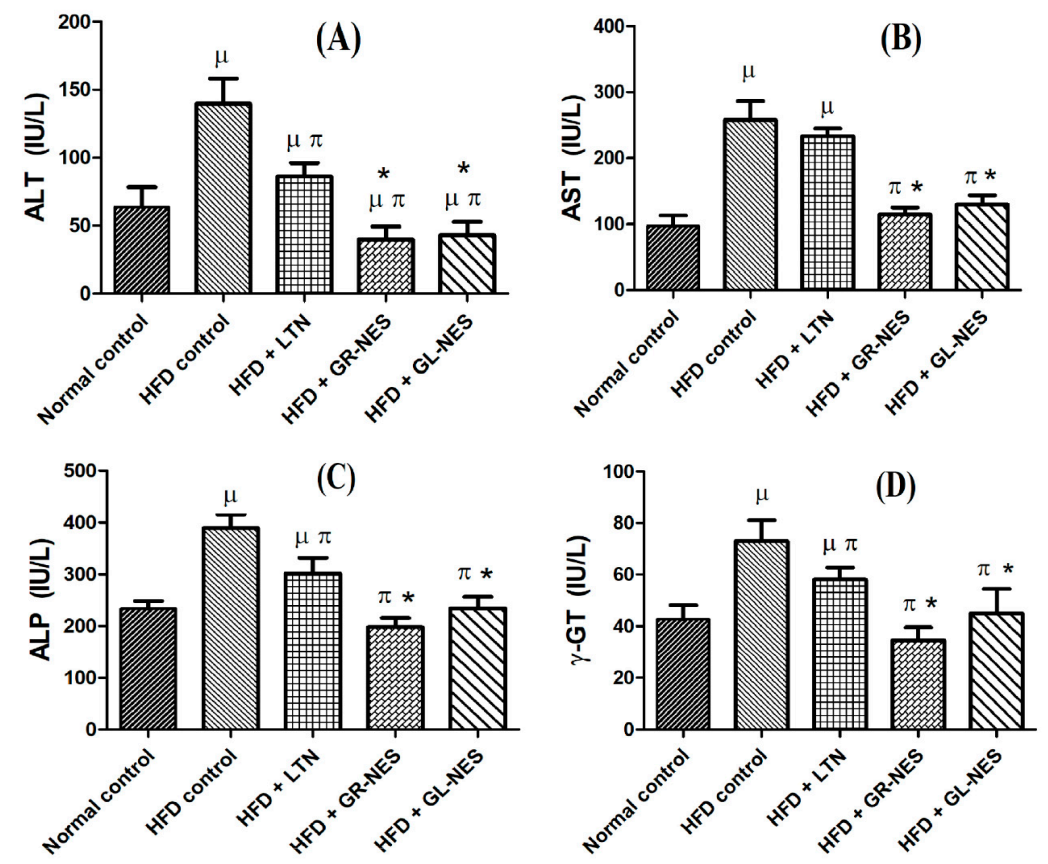

Figure 4. (A) Serum ALT; (B) Serum AST; (C) Serum ALP; (D) serum $\gamma$-GT levels of nanoformulations and pure LTN in hyperlipidemic rat models $(n=6)$ after 4 weeks of oral administration (dose $=30 \mathrm{mg} / \mathrm{kg} / \mathrm{d}) . \mu$ indicates $p<0.05$ vs. normal control; $\pi$ indicates $p<0.05$ vs. HFD control; * indicates $p<0.05$ vs. HFD + LTN.

\subsubsection{Aspartate Aminotransferase (AST or SGOT)}

The serum AST level of group A was $98 \pm 16.09 \mathrm{IU} / \mathrm{L}$, while that of group B was $257 \pm 28.75 \mathrm{IU} / \mathrm{L}$. There was a highly significant difference between AST values of groups A and B $(p<0.001)$, indicating drastic effects of a high-fat diet on normal liver functions (Figure 4B). Among all treated groups (C, D, and $\mathrm{E})$, groups $\mathrm{D}$ and $\mathrm{E}$ showed significant reductions $(p<0.05)$ in AST levels in comparison to group B. After completion of the experiment, their AST levels were $121 \pm 10.05$ and $143 \pm 14.5$ IU/L, respectively. Animals of group C did not display a significant reduction in AST levels when compared with group $\mathrm{B}$, but these levels were significantly higher than those of groups D and E $(p<0.05)$.

\subsubsection{Alkaline Phosphatase (ALP)}

Groups D and E were found to be most effectively protected after completion of the experiment. Both groups showed serum ALP levels after termination of the animal study at $196 \pm 17.7$ and $234 \pm 22.15 \mathrm{IU} / \mathrm{L}$, respectively. Their ALP levels seem to be in range of normal control group A $(227 \pm 15.05 \mathrm{IU} / \mathrm{L})$. HFD group B showed a marked difference from group A (171\% higher level) (Figure 4C). Four-week-long administration of GR and GL oil formulations showed respective $40 \%$ and $50 \%$ decreases in ALP levels as compared to group B. This proved the ameliorative effect of GR and GL oil formulations on normal functioning of liver enzymes. 


\subsubsection{Gamma Glutamyl Transpeptidase $(\gamma-\mathrm{GT})$}

Figure $4 \mathrm{D}$ displays serum $\gamma$-GT levels of all groups. It is evident that group B showed significantly $(p<0.05)$ higher levels of serum $\gamma$-GT as compared to group A, which was due to a high fat intake leading to hepatic damage. On the other hand, groups $C, D$, and $E$ showed normalized values of serum $\gamma$-GT, indicating that treatment was beneficial for liver function. Among all treated groups, GR and GL oil nanoemulsomes exerted a comparatively better recovery as compared to LTN alone.

\subsection{Renal Function Tests (RFTs)}

Various serum biomarkers were measured to observe normal or abnormal renal functioning after consumption of a fat-rich diet. Serum creatinine, blood urea, BUN, serum proteins, albumin to globulin $(\mathrm{A} / \mathrm{G})$ ratio, and serum calcium were analyzed. Results show that group B was more prone to develop kidney disease or nephrotoxicity. Serum creatinine, blood urea, and BUN levels of group B were much higher $(p<0.05)$ at $143 \%, 116 \%$, and 199\%, respectively, than those of normal control group A, indicating establishment of nephrotoxic conditions and renal impairment in rats fed with a high-fat diet (Table 3).

Table 3. Effect of nanoformulations and pure LTN on serum biomarkers for kidney functions in hyperlipidemic rat models $(n=6)$ after 4 weeks of oral administration (dose $=30 \mathrm{mg} / \mathrm{kg} /$ day).

\begin{tabular}{cccc}
\hline Groups & Serum Creatinine $(\mathbf{m g} / \mathbf{d L})$ & Blood Urea $(\mathbf{m g} / \mathbf{d L})$ & BUN $(\mathbf{m g} / \mathbf{d L})$ \\
\hline Normal control (A) & $0.32 \pm 0.04$ & $46 \pm 4.50$ & $21.5 \pm 4.28$ \\
HFD control (B) & $0.46 \pm 0.07^{*}$ & $51 \pm 5.31 *$ & $42.9 \pm 8.03^{*}$ \\
HFD + LTN (C) & $0.41 \pm 0.04$ & $48 \pm 3.41^{*} \# \mu$ & $30.3 \pm 4.75^{*} \#$ \\
HFD + GR-NES (D) & $0.30 \pm 0.03 \#$ & $31 \pm 2.73^{*} \# \mu$ & $14.7 \pm 2.55 \# \mu$ \\
HFD + GL-NES (E) & $0.34 \pm 0.03 \#$ & $38 \pm 3.71 * \#$ & $21.2 \pm 3.03 \#$ \\
\hline
\end{tabular}

${ }^{*}$ indicates $p<0.05$ vs. normal control; \# indicates $p<0.05$ vs. HFD control; $\mu$ indicates $p<0.05$ vs. HFD + LTN.

Blood urea levels of groups D and E showed respective $40 \%$ and $24 \%$ reductions $(p<0.05)$ when compared to those of HFD control group B. Differences between blood urea levels of groups B and C $(6 \%)$ were not significant $(p>0.05)$. Blood urea levels of groups B and $C$ were significantly different $(p<0.05)$ from those of normal control group A. Except for group C, serum creatinine levels of groups D and E illustrated significant decreases $(p<0.05)$ as compared to those of HFD group B ( $35 \%$ and $23 \%$ lower than group B, respectively).

BUN levels of groups D and E did not display significant differences $(p>0.05)$ with group A, while group $C$ showed a significant difference $(p<0.05)$ with group A. There were significant differences $(p<0.05)$ in BUN levels of groups C, D, and E when compared with those of HFD group B. BUN levels of groups D and $\mathrm{E}$ reduced up to $66 \%$ and $51 \%$, respectively, as compared to group B.

Serum proteins are taken as a direct measure of normal renal functionality. Results showed that serum total proteins, serum albumin, and A/G ratio of HFD group B were significantly different $(p<0.05)$ from that of group A (Table 4). Their values were $44 \%, 54 \%$, and $17 \%$ lower, respectively, as compared to normal diet group A. Whereas, serum globulin of HFD group B was $304 \%$ greater than that of group A. These results demonstrate the prevalence of kidney disease in hyperlipidemic rats.

Groups treated with the LTN suspension and drug-loaded GR and GL oil nanoemulsomes demonstrated improved kidney functions by the normalized values of these biomarkers, but they showed significant differences $(p<0.05)$ with HFD group B. Group C registered an increase of $194 \%$, $137 \%$, and $374 \%$ in total proteins, serum albumin, and $A / G$ ratio, respectively, while a decrease of $36 \%$ was seen in serum globulin levels as compared to group B.

Groups D and E also manifested amelioration of $208 \%$ and $180 \%$ in total proteins, $162 \%$ and $131 \%$ in serum albumin, and $414 \%$ and $319 \%$ in the $\mathrm{A} / \mathrm{G}$ ratio, respectively, as compared to HFD group B. Furthermore, there were decreases of $39 \%$ and $33 \%$ in serum globulin levels of groups D and E, respectively, as compared to group B. 
Table 4. Effect of nanoformulations and pure LTN on serum biomarkers for kidney functions in hyperlipidemic rat models $(n=6)$ after 4 weeks of oral administration (dose $=30 \mathrm{mg} / \mathrm{kg} / \mathrm{d}$ ).

\begin{tabular}{ccccc}
\hline Groups & $\begin{array}{c}\text { Serum Protein } \\
(\mathbf{g} / \mathbf{d L})\end{array}$ & $\begin{array}{c}\text { Serum Albumin } \\
\mathbf{( g / d L})\end{array}$ & $\begin{array}{c}\text { Serum Globulin } \\
\mathbf{( g / d L})\end{array}$ & A/G Ratio \\
\hline Normal control (A) & $7.6 \pm 0.76$ & $4.92 \pm 0.63$ & $2.62 \pm 0.40$ & $1.8 \pm 0.20$ \\
HFD control (B) & $3.4 \pm 0.93 *$ & $2.67 \pm 0.46^{*}$ & $7.98 \pm 0.54 *$ & $0.33 \pm 0.07^{*}$ \\
HFD + LTN (C) & $6.6 \pm 0.65 \#$ & $3.67 \pm 0.38 \#$ & $2.93 \pm 0.45 \#$ & $1.25 \pm 0.16 \#$ \\
HFD + GR-NES (D) & $7.1 \pm 0.58 \#$ & $4.34 \pm 0.50 \#$ & $3.13 \pm 0.60 \#$ & $1.38 \pm 0.28 \#$ \\
HFD + GL-NES (E) & $6.14 \pm 0.46 \#$ & $3.5 \pm 0.68 \#$ & $2.64 \pm 0.42 \#$ & $1.32 \pm 0.20 \#$ \\
\hline \multicolumn{4}{r}{${ }^{*}$ indicates $p<0.05$ vs. normal control; \# indicates $p<0.05$ vs. HFD control. }
\end{tabular}

\subsection{Histopathological Examination}

Histopathological results of liver sections of normal control diet group A (Figure 5A) indicated normal hepatocytes with prominent nuclei and preserved cytoplasmic structures without the occurrence of ballooning or necrotic effects. Nuclei in these hepatocytes were not displaced, and cellular structures were well maintained. H\&E sections of animal livers maintained on a hyper fat diet (group B) indicated swollen globular sacs (ballooning effect) with major nuclei displacements and hepatocytic degenerative effects (Figure 5B), demonstrating the accumulation of excess fatty acids. Liver sections of group C, treated with LTN suspension, also claimed nuclei displacements, but there were mild ballooning degenerative effects (Figure 5C) as compared to group B on liver parenchyma cells, indicating ameliorative effects of LTN towards damaged liver cells but not yet fully recovered. Both GL and GR oil LTN-loaded nanoemulsomes imparted magnificent curative results, as liver sections of these groups (D and E) displayed a well-organized structure of hepatocytes along with established cytoplasmic material (Figure 5D,E).

(A)

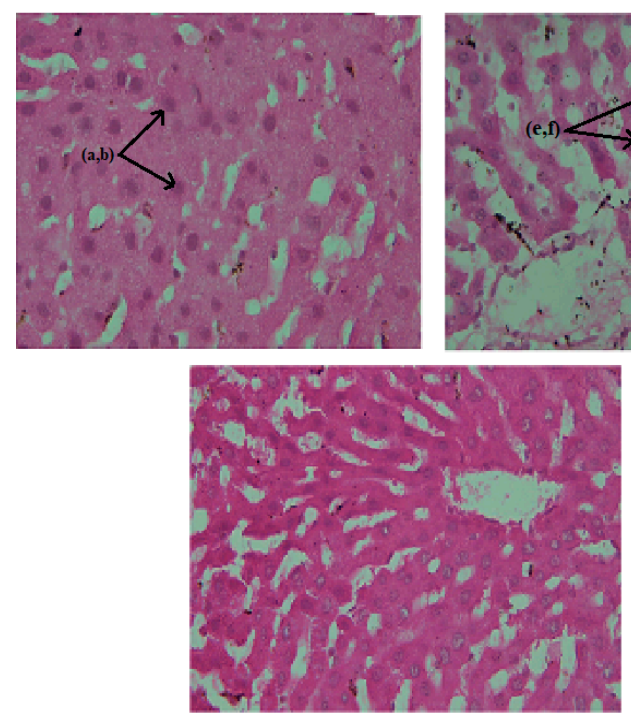

(D)
(B)

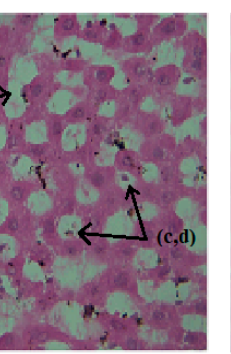

(C)

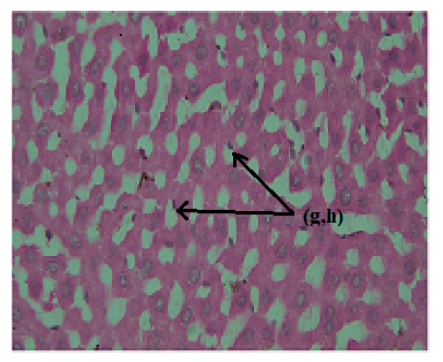

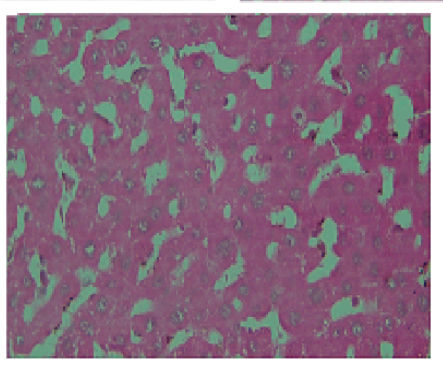

(E)

Figure 5. (A) Liver section of a rat of from the normal diet group, arrows (a, b) indicate localized nuclei with well-established cytoplasm; (B) liver section of a rat kept on a high-fat diet, arrows (c, d, e, and f) demonstrate bulged out, fat-filled large sacs (ballooning) and major displacements of cell nuclei; (C) liver sections of LTN-treated rats indicating mildly fat-filled or microvesicular structures with displaced cell nuclei (arrows g, h); (D) liver section from the GL oil LTN-loaded nanoemulsome treatment group claiming no vesicular ballooning or fat accumulation; (E) liver section from the GR oil LTN-loaded nanoemulsome treatment group displaying cytoplasmic preservation with no fat deposition but minute displacement of cell nuclei. 
Histopathology of H\&E stained kidney sections of experimental rats from control group A (Figure 6A) demonstrated normal kidney structures, as the glomeruli of these rats were found to be in proper shape and in preserved form, with no dilation of interstitial blood vessels and renal tubules, indicating normal functioning of kidneys in these rats. While in the case of group B (HFD group), H\&E stained kidney sections showed degenerated glomerular structures (dilated glomerular capillaries) along with dilated blood vessels and unpreserved renal tubules (distal and proximal tubules) with enlarged lumen (Figure 6B). Group C, which was treated with pure LTN suspension, displayed improved glomeruli, but renal tubules remained unpreserved due to the effect of the high-fat diet (Figure 6C). Glomerular capillaries were also dilated, but to a lesser degree, as compared to those in group B. Groups D and E showed that glomerular structures in both groups were in a far better position and were comparable to that in normal control group A (Figure 6D,E). Both groups demonstrated a well-preserved renal tubular system with no blood vessel dilations.

(A)

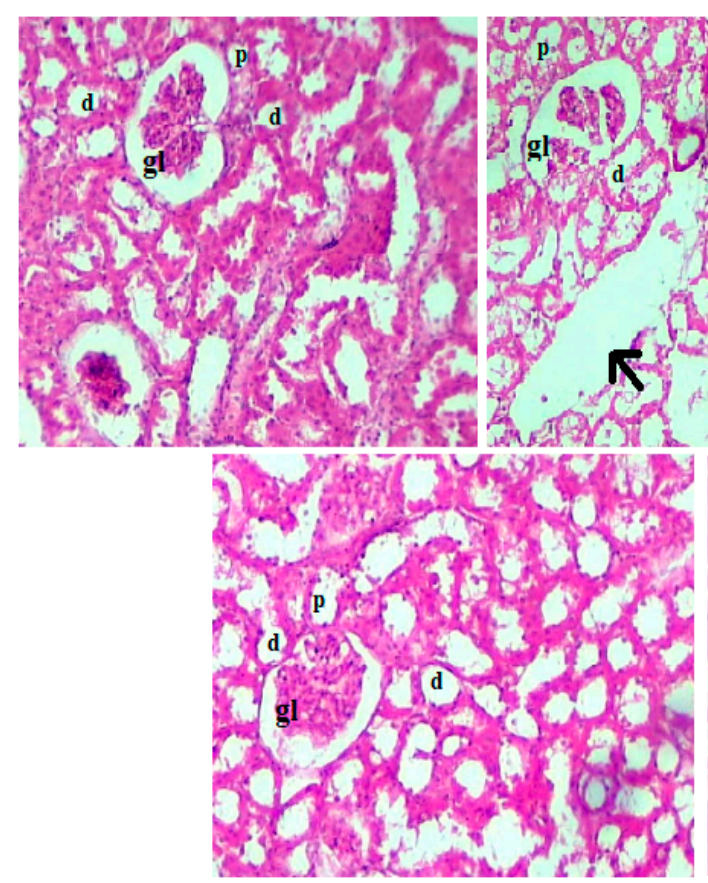

(D)
(B)

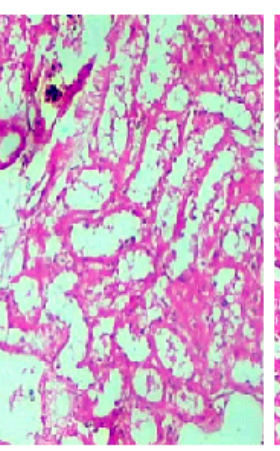

(C)

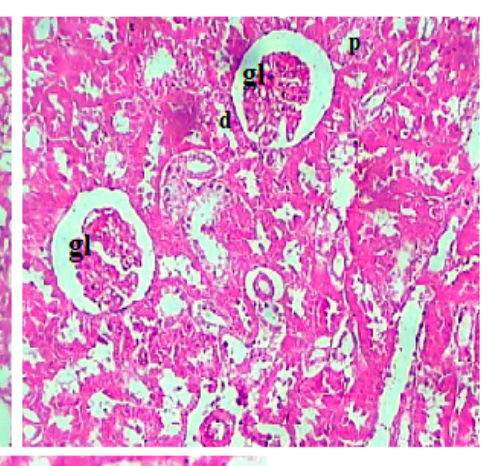

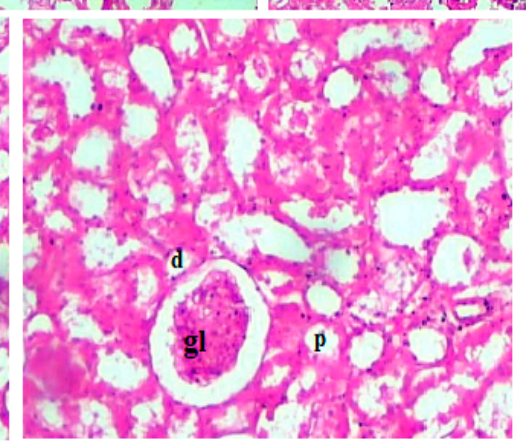

(E)

Figure 6. (A) Kidney section from the normal control group. (B) Kidney section from the high-fat diet group. Arrow indicates enlarged blood vessels. (C) Kidney section of the LTN-treated group. $(D, E)$ Kidney sections of animals treated with garlic and ginger oil LTN-loaded NESs, respectively. Black arrows indicate dilated blood vessels. d; distal convoluted tubule. p; proximal convoluted tubules. gl; glomerulus.

\section{Discussion}

\subsection{Body Weight of Animals}

Among animal obesity models, rats that are fed a continuous hyper fat diet are usually preferred because they develop NAFLD by long-term consumption of a high-fat diet leading to a hyper body weight, increased lipid levels, boosted arterial deposition of cholesterol, hepatic steatosis, and dyslipidemia [38]. In our study, group A sustained normal body weight throughout experiment, while hyper fat diet consumption in rats (group B) resulted in tremendous weight gain of about $200 \%$ as a consequence of high energy intake and mass building, which is attributed to saturated fat deposition in different body fat pads [39]. This high level gain in body weight stipulates two mechanisms of adiposity: increase in cell number (hyperplasticity) and increase in cell size (hypertrophy) [40]. 
Groups C, D, and E also showed similar patterns as group B until week 4, when treatment was started. After the first week of treatment, groups treated with drug-loaded GR and GL oil nanoemulsomes showed decreases in percent body weight, which were attributed to the synergistic antiobesity effects of LTN and active constituents present in these oils. Group D treated with GR oil LTN-loaded nanoemulsomes was significantly different $(p<0.05)$ from the hyper fat diet group B in terms of body weight percent and substantially lowered the body weights of these animals. This is due to the presence of 6-gingerol, which might have caused hypophagic effects in obese animals [41].

GR also produces hurdles in absorption of dietary fats by retarding fat hydrolysis, which results in loss of adipose tissue weight [42]. GR aqueous and alcoholic extracts have been shown to produce effective antiobesity effects in animals [42]. Likewise, GL oil drug-loaded nanoemulsome treatment group E also showed reduction in body weight percent after initiation of treatment. This is because of DADS, a highly active organosulfur compound of GL, which helps in lowering diet-induced body weight and adipose tissue weight as well [43].

\subsection{Lipid Profile}

Globally, dyslipidemia is known to be an established cardiovascular risk factor, and, if left uncured, its persistence causes fatalities like atherosclerosis and chronic heart disease [44]. Results obtained from animal serum data analyses provide satisfactory evidence of ameliorating biochemical parameters of the lipid profile (i.e., TC, LDL-C, vLDL-C, HDL-C, TG, and AI). Lower serum TC levels in groups treated with drug-loaded nanoemulsome formulations indicate enhanced and prolonged effects of LTN because of their raised carrying capacity of hydrophobic moieties [45]. It is evident from the results that there was a significant reduction $(p<0.05)$ in serum TC levels of groups D and E as compared to those of group B and the group treated with pure LTN suspension, which indicates significant effects on the cholesterol metabolic sites by nanoemulsomes.

There are number of reported studies in which these oils have markedly reduced serum TC levels in hypercholesterolemic animal models $[4,46]$. A possible explanation for the greatly lowered serum TC levels of groups D and E may be the synergistic effects of LTN combined with these essential oils. GR essential oil contains numerous polyphenolic and other volatile constituents like geranaiol, citral, gingerol, zingeberene, $\beta$-funebrene, citronellyl n-butyrate, $\alpha$-Pinene, and camphene, which have proven to be effective in lowering serum TC levels in hypercholesterolemic animals [47]. Decreased levels of TC of group D might have originated from HMG-Co-A reductase inhibitory effects of one of the components of GR (i.e., aframodial [48]).

10-dehydrogingerdione, another component isolated from GR, has reportedly decreased TC levels of hypercholesterolemic rats by inhibiting cholesteryl ester transfer proteins (CETP), which are proteins that help reverse transport of cholesteryl ester from HDL-C towards triglyceride-rich lipoproteins (LDL-C and vLDL-C) [49]. This component of GR has also been shown to raise HDL-C levels [50]. Previously, GR and GL oil components have been shown to be effective in decreasing TC levels and improving the lipid profile in hyperlipidemic rat models by retarding the activities of several enzymes that are directly involved in cholesterol synthesis like SREBP1-c and ACC [4,12].

GR constituents also alleviate TC levels via another reported mechanism of upgrading hepatic cholesterol $7 \alpha$-hydroxylase activity. This is a rate-limiting enzyme in the conversion of serum free cholesterol to bile acids and downregulating HMGR genes (responsible for encoding rate-limiting enzymes in cholesterol biosynthesis), hence lowering serum TC and the risk of coronary heart disease [48,51]. Remarkably reduced levels $(p<0.05)$ of vLDL-C, LDL-C, and triglycerides and elevated levels of HDL-C can be explained by the presence of niacin in GR extracts. Niacin helps to clear vLDL-C, attenuate serum TG levels, and boost hepatic LDL-C uptake and downregulate its oxidation process as well [52]. Gingerol, another component of GR oil, tends to amend the lipid profile by boosting HDL-C levels and helps reduce absorption of plasma and tissue cholesterol via inhibition of pancreatic lipase [46]. 
Group E treated with nanoemulsomes carrying GL oil as liquid lipid also showed markedly reduced $(p<0.05)$ levels of TC and a revamped lipid profile of hypercholesterolemic rat models as compared to group B and the LTN-treated group. Organosulfur compounds in GL tend to refine antioxidant properties by increasing glutathione levels and antioxidant enzyme activity as well as relieving lipid peroxidation [53,54]. Certain constituents (allicin, DADS, and allyl mercaptan) of GL inhibit biosynthesis of cholesterol directly by inhibiting HMG-Co-A reductase [55].

Allicin and DADS have shown to lower levels of free fatty acids (FFAs), and body weight as well, owing to reduced adipose tissues over the continuous administration of drug-loaded GL oil nanovesicular lipoidal formulations. This decreased weight after the fourth week of study could be attributed to the anti-hyperlipidemic and antiobesity effects of GL, and it has a direct link in reducing LDL-C, vLDL-C, and TG levels [43]. In a study, a commercially available combination (PENNEL ${ }^{\circledR}$ ) of GL oil and dimethyl-4,4-dimethoxy-5,6,5,6-dimethylenedioxybiphenyl-2,2-dicarboxylate (DDB) significantly reduced serum TG levels [56]. Similar to GR oil, GL oil has also been reported in eliminating atherosclerotic effects and lowering AI by inhibiting CETP and improving serum HDL-C levels [57].

GL oil manipulates biosynthesis of cholesterol and bad lipids by directly inhibiting the number of enzymatic processes, which involve inhibition of fatty acid synthase, glucose- 6 phosphate dehydrogenase (G-6 PDH), and malic enzyme as well. Therefore, in our study, GL substantially assisted LTN in directly blocking HMG-Co-A reductase and showing synergy via reported mechanisms [58]. GL oil LTN-loaded nanoemulsomes showed significantly reduced TC levels, while HDL-C levels were boosted. This can be attributed to the cholesterol excretion mechanism of GL, which manifests in elimination of acidic and neutral steroids, and also because of reduced vLDL-C fractions and HDL-C-induced removal of cholesterol from arterial tissues [57]. Since GL oil contains allicin, it exerts antioxidant effects towards LDL-C, making it possible to alleviate the risk of atherosclerosis [59].

Anti-hyperlipidemic agents work by either lowering the bad lipids (TG, LDL-C, and vLDL-C) or by increasing the good lipids (HDL-C) in plasma, or a combination of both. Our study demonstrated that both GL and GR decreased the bad lipids and increased the good lipids at the same time. However, GR was superior in lowering the bad lipids than GL, and GL was quite better in improving the good lipids as compared to GR. With this in mind, AI, a measure of the overall atherogenic potential, is the ratio of bad lipids to good lipids. Thus, AI results of this study reveal that GR-NES was comparatively good at lowering the risk of atherogenesis than the GL-NES. The risk of coronary heart disease increases with an increased presence of atherosclerosis, which manifests as depositions of bad cholesterol and fats on the walls of arteries. Hence, AI is usually considered as a stand-alone index to evaluate cardiovascular risk factors when all other parameters of the serum lipid profile are ruled out or insufficient in providing necessary information [60]. LTN has proved to be an effective agent in improving the lipid profile in hypercholesterolemic or dyslipidemic animal models, hence leading to reduced risk of AI [61]. In our study, LTN along with GR and GL oils (drug-loaded nanoemulsomes) provided the best treatment in scaling down AI of animals kept on a high-fat diet. This is regarded as the direct action of LTN in improving the lipid profile of hyperlipidemic rats in synergy with parallel effects of GR and GL oil constituents, hence, lowering the risk of AI by decreasing LDL-C and VLDL-C while improving HDL-C levels [12]. In this study, we also considered the TG/HDL-C ratio as the surrogate indicator for insulin resistance as suggested in recent literature [33]. GR-NES and GL-NES were much better than LTN alone in reversing insulin resistance. Nanosomal formulations reduced insulin resistance in hyperlipidemic rats to the same level as that of the rats fed on a normal or control diet. Our findings comply well with the reported anti-insulin resistant properties of both GR [62] and GL [63].

\subsection{Liver Function Analyses (LFTs)}

The liver is known to be the main site for biosynthesis and metabolism of number of molecules. Any damage to it leads to abnormalities in normal physiological functions of body. Excess intake of a diet rich in fatty acids deteriorates the normal functioning of hepatocytes. High-fat diet induces 
changes in the normal physiology of hepatocytes, by depositing fat inside them, as it exerts pressure on cell linings and makes them leaky [37]. Since alkaline phosphatase (ALP) is a membrane-bound enzyme and found to be in abundance in hepatocyte cell membranes, it tends to escape cells once they become leaky, therefore ALP levels are high in animals that have been fed a high-fat diet [64]. While AST and ALT are abundantly found enzymes in kidney and liver only, their high serum concentrations occur when cellular gateways are open or are made open by physiological or toxicological changes in normal cell functions [65]. This evidence helps understand our findings of the high serum AST and AST levels in the HFD group thatexcess feeding of a fat-rich diet led to ample amounts of saturated fat inside the hepatocytes, acquiring enormous space, and making cell membranes leaky by pushing cellular material to the peripheries. High serum concentrations of these localized enzymes illustrate HFD induced insult and damage to cell membranes [37].

Hence, administration of LTN-loaded GR and GL oil lipoidal nanovesicular systems boosted the healing process of HFD-ruptured cell membranes and helped lower serum concentrations of AST, ALT, GGT, and ALP. Dietary lipids have shown to boost the regulation of membrane lipid composition, which ultimately helps in controlling the activity of membrane proteins like ALP [66]. GR has improved the serum profiles of AST, ALT, GGT, and ALP by healing hepatocyte membranes, as GR is known to be a highly hepatoprotective neutraceutical agent. GR has previously shown marked protection of liver cells from injuries with an accelerated healing process by uplifting the activity of the antioxidant enzyme (superoxide dismutase (SOD)) and by slowing the lipid peroxidation processes [67]. The antioxidant activity of GR oil resembles that of vitamin $C$ in lowering lipid peroxidation by impacting serum catalase and SOD enzyme concentrations [68]. GR oil nanoemulsomes also significantly $(p<0.05)$ reduced serum GGT levels, owing to its antioxidant ability [16].

GR extracts have also been effective in regenerating parenchyma cells, protecting against membrane fluidity and fragility, and promoting rapid normalization [69]. Our results of lower AST, ALT, and ALP activities in improving cellular health and minimizing leakage from hepatocytes upon administration of GR oil nanoemulsomes are also in accordance with previous studies [70]. Two grams of GR powder, when administered for about 12 weeks, led to significantly reduced serum levels of ALT in NAFLD patients [71]. Atorvastatin and GR extract were shown to promote recovery of cell membranes from leakage defects and downregulated the activities of AST, ALT, GGT, and ALP by inhibiting their escape from ruptured hepatocytes [72].

In a recent study, GL oil significantly alleviated AST, ALT, GGT, and ALP concentrations to satisfactory levels by providing recovery to damaged cell linings of liver cells and because of its antioxidant activities (i.e., uplifting activity of SOD enzyme [73]). Hepatotoxicity induced by paracetamol was cured, and hepatocytes were protected from injury by administration of GL extract. This finding was attributed to GL oil, as it contains S-allyl cysteine (SAC) and S-allylmercapto cysteine (SAMC). These two constituents of GL oil, especially SEMC, tend to impart hepatoprotective properties to the injured cell membranes [22]. DAS, being an important and major component of GL oil, has shown revamped results in ameliorating stress-induced or alcohol-induced fatty liver disorders. It directly inhibits the P450 2E1 enzyme, which is involved in lipid peroxidation intoxication of a number of metabolic toxic products in such abusive conditions that cause further damage to cell physiology.

Previous research works showed that DAS has successfully inhibited or downregulated the activity of the CYP2E1 enzyme upon administration of GL oil in hepatic disease conditions [74]. Enzyme CYP2E1 is actively involved in the metabolism of a number of small toxic molecules like $\mathrm{CCL}_{4}$. Inhibition of this enzyme by GL indicated improved hepatocyte histopathology and also decreased serum levels of AST, ALT, GGT, and ALP. This pharmacological action of GL oil is attributed to the presence of highly antioxidant organosulfur compounds found in it (AS, DAS, and DADS) [56]. Likewise, citral (a component of GR) has also been revealed to reverse CYP2E1 activity in a dose-dependent manner, where moderate to higher doses of citral and GR essential oil substantially turned off this enzyme's activity [4]. 


\subsection{Renal Function Tests (RFTs)}

Chronic dietary lipid intake leads to excess deposition of saturated fats inside the cells of various organs. Lipids are deposited in the kidney at a high level, leading to significant alterations in renal subcellular structures (renal cortex) [75]. Enormous adiposity leads towards dilation of large localized blood vessels, and subcapsular adipocyte accumulation causes glomerular atrophy and necrosis, resulting in poor filtration of a number molecules and, consequently, raising their plasma levels [76]. Vasculature abnormalities and nephropathy, owing to a high intake of saturated fatty acids, has also been reported [77]. Hypercholesterolemia, hypertriglyceridemia, low levels of HDL-C, and high concentrations of apolipoprotein-B are known as major risk factors in the development of chronic kidney disease (CKD). Moreover, in the presence of these abnormalities, kidney disease progresses more rapidly [78]. Such nephrotoxic and abnormal conditions lead to malfunctioning of kidneys and cause an imbalance in concentrations of small molecules and electrolytes inside and outside the cells [79].

Elevated levels of blood urea and creatinine are direct indicators of renal injury due to enhanced xanthine oxidase, TG, and cholesterol levels, and this indicates uplifted lipid peroxidation in hypercholesterolemic rats $[9,80]$. It is evident from the results that group $\mathrm{B}$, which was kept on a high-fat diet throughout the experiment, showed comparatively higher levels of serum creatinine, blood urea, serum total calcium, decreased serum total proteins, and albumin-globulin (A/G) ratio. Whereas, the levels of these biochemical parameters in groups treated with LTN-loaded GR and GL oil nanoemulsomes (groups D and E) were quite lower compared to the HFD group. The reason behind this is the direct action of these natural therapeutic agents in remediation of injured cell lines and damaged organs.

GR aqueous and alcoholic extracts have been shown to normalize levels of these biomarkers and heal the damaged site [81]. GR contains polyphenols and flavonoids, which provide antioxidant and nephroprotective effects and help regulate the normal functioning of nephrons [82]. This prevents elevations in blood urea and serum creatinine levels and reductions in serum proteins and albumin leakage into urine (increase in the $\mathrm{A} / \mathrm{G}$ ratio). Hence, it normalized the levels of these biomarkers as compared to HFD group B. GR is widely known as a blood cleaner when it comes to elevated levels of blood urea and serum creatinine; hence, it keeps normal concentrations of these biological compounds by eliminating them when their concentration goes higher in diseased conditions [83].

Gingerol has been designated as a potent chemical in downregulating inflammatory gene expressions at the site of injury, and it protects against oxidative stress by dwindling the concentration of nitric oxide (NO) [34,84]. HFD group B showed reduced levels of serum proteins and the A/G ratio, indicating greater removal of proteins (total proteins and albumin) into urine as a result of leaky glomerular linings and tubules [80]. Group D showed reduced leakage, normal levels of the proteins, and a comparatively higher $A / G$ ratio in serum, owing to GR's amending properties on injured organs [81].

Both GL and GR oil nanoemulsomes caused reductions in creatinine levels, as the body weights of these groups decreased. This evidence is in accordance with a previous report [85]. Lipids play a major role in the establishment of glomerular disease, and all lipid-lowering agents are involved in protecting the kidney from getting injured. LTN indirectly protects the kidneys from nephritic conditions by ameliorating glomerulosclerosis and by inhibiting ingestion of lipoproteins in mesangial cells and preventing binding of these lipids to glomerular epithelial cell linings $[25,86]$. Besides, statins have also shown their direct effect in retarding progression of CKD via a number of mechanisms [23,87]. Simvastatin and fluvastatin have directly imparted renoprotective effects in clinical trials by combating dyslipidemia and reversing proteinuria [88]. This evidence seconds our findings on the synergistic effects of LTN with GR or GL oils in regulating renal functions.

Gulaz et al. found out that GL oil protects kidneys from damage and does not allow any alterations in the sizes of glomeruli in rats induced with acetaminophen nephrotoxicity. GL oil improved the functioning of glomeruli in comparison to diseased ones. Animal urea, A/G ratio, and serum creatinine 
levels were also found to be in normal ranges as compared to diseased animals, owing to the antioxidant properties of organosulfur compounds of GL oil [89]. GL aqueous extract has helped in the recovery from glomerular ischemia and free radical induced oxidative stress and has also improved BUN, blood urea, and serum creatinine levels [90]. GL has also been reported to restore serum levels of biomarkers of normal renal functions by protecting glomeruli from reactive oxygen species (ROS) by boosting levels of antioxidant enzymes [91]. DADS has also been widely approved for its antioxidant activity and beneficial role in protecting the kidney from nephrotoxicity [21].

\subsection{Histopathology}

Obesity, hypercholesterolemia or hyperlipidemia, and genetically altered fatty acid metabolism are considered to the major causes of fatty liver disease (FLD) [92]. If left untreated, these conditions may lead to the occurrence of liver cirrhosis, liver cancer, and steatohepatitis [93]. In this study, liver sections of animals fed on a hyper fat diet (Figure 5B) showed excess accumulation of lipids (lipid-filled macrovesicular structures), indicating prevalence of hepatic steatosis and hepatic necrosis (excessive fat deposition in hepatocytes appearing as a rounded ring with a swelled vacuole and displaced cell nuclei) [94]. This evidence proves the occurrence of fatty liver disease in hypercholesterolemic rats. Liver sections of group C animals treated with LTN suspension alone (Figure 5C) exerted slight curative effects in reducing fat accumulation, but they also showed fat-filled sacs of reduced sizes as compared to ones that appeared in the high-fat diet group B. Generally, hepatosteatosis takes place because of the presence of microvesicular small fat droplets that are responsible for filling hepatocyte cytoplasm without a central location of the nucleus [95]. Liver sections treated with GL and GR oil LTN-loaded nanoemulsomes (groups D and E) showed substantially improved histological features with preserved cytoplasmic material and demonstrated no existence of fat-filled large or small vesicles. Nuclei in these sections (Figure 5D,E) look active and larger (vesicular) with a normal appearance of blood sinusoids, which describes the restorative effects of LTN on hepatocytes in synergy with GR and GL oils [70].

According to a recent report, obesity bears a direct link in establishing metabolic syndrome in effected individuals, which leads to CKD and damages the functional units of kidneys (glomeruli and renal tubules). It manifests because of ROS produced in response to hyperlipidemic stress and kidney injuries due to high fat accumulation [96]. Group B illustrated enlarged renal blood vessels as well as degenerated and dilated glomerular capillaries and renal tubules (Figure 6B) associated with fat accumulation [76]. Group C (Figure 6C) displayed improved morphology of glomerular capillaries as compared to the HFD group. This improvement is attributed to the direct renoprotective effect of LTN [25]. Histopathological findings indicate improved and preserved kidney structures for NES-treated groups. This can be attributed to the renoprotective effects of active compounds (flavonoids steroids and alkaloids) found in ginger that help mop up free radical generation and protect the kidney from injury [97]. The renoprotective activity of garlic's sulfur containing compounds (DAS and allicin), which tend to inhibit the production and activity of ROS produced in response to hypercholesterolemic renal injuries [98], might also explain the performance of GL-NES.

\section{Conclusions}

Data of the current study demonstrate that co-encapsulation of LTN with natural therapeutic oils (GR or GL) in a lipoidal nanovesicular delivery system results in significant improvement in the therapeutic efficacy of standard anti-hyperlipidemic drugs. This improvement in the anti-hyperlipidemic profile is suggested to be due to the presence of multiple active components. Exploiting the curative effects of such oils, along with a pharmaceutical active moiety, not only allows better control of the diseased state but also provides protection to the key organs. Hence, the synergistic activity of nutraceutical and pharmaceutical ingredients leads to a successful therapy with a quick and efficient recovery. This could lead to a reduction in the dose of the given drug, consequently decreasing the drug-associated side effects. Hence, we conclude that GR and GL oil LTN-loaded nanoemulsomes could be an effective strategy against hyperlipidemia and associated complications, which involves the 
use of naturally occurring therapeutic constituents in tandem with the drug to improve the overall therapy and, hence, patient compliance [99].

Author Contributions: Conceptualization, S.A.; Data Curation, S.A.F., S.H.K., I.U.K., I.K. and U.F.G.; Formal Analysis, S.A.F., S.A. and T.H; Methodology, S.A.F., S.A., S.H.K., M.A. and I.K; Investigation, S.A.F., S.A., M.A. and T.H.; Writing-Original Draft, S.A.F. and S.A.; Writing-Review and Editing, S.A.; Supervision, S.A.

Funding: This study is funded by HEC, Pakistan, Project \# 5663/Punjab/NRPU/R\&D/HEC/2016.

Acknowledgments: The authors thank Nabiqasim Industries, Pakistan for providing free sample of LTN. The authors are also grateful to Lipoid AG, Switzerland for providing Phospholipon $90 \mathrm{G}$.

Conflicts of Interest: The authors declare no conflict of interest.

\section{References}

1. Canbakan, B.; Tahan, V.; Balci, H.; Hatemi, I.; Erer, B.; Ozbay, G.; Sut, N.; Hacibekiroglu, M.; Imeryuz, N.; Senturk, H. Leptin in nonalcoholic fatty liver disease. Ann. Hepatol. 2008, 7, 249-254. [CrossRef]

2. Power, M.L.; Schulkin, J. Sex differences in fat storage, fat metabolism, and the health risks from obesity: Possible evolutionary origins. Br. J. Nutr. 2008, 99, 931-940. [CrossRef] [PubMed]

3. Chalasani, N.; Younossi, Z.; Lavine, J.E.; Diehl, A.M.; Brunt, E.M.; Cusi, K.; Charlton, M.; Sanyal, A.J. The diagnosis and management of non-alcoholic fatty liver disease: Practice Guideline by the American Association for the Study of Liver Diseases, American College of Gastroenterology, and the American Gastroenterological Association. Hepatology 2012, 55, 2005-2023. [CrossRef] [PubMed]

4. $\quad$ Lai, Y.-S.; Lee, W.-C.; Lin, Y.-E.; Ho, C.-T.; Lu, K.-H.; Lin, S.-H.; Panyod, S.; Chu, Y.-L.; Sheen, L.-Y. Ginger essential oil ameliorates hepatic injury and lipid accumulation in high fat diet-induced nonalcoholic fatty liver disease. J. Agric. Food Chem. 2016, 64, 2062-2071. [CrossRef] [PubMed]

5. Malaguarnera, M.; Di Rosa, M.; Nicoletti, F.; Malaguarnera, L. Molecular mechanisms involved in NAFLD progression. J. Mol. Med. 2009, 87, 679-695. [CrossRef] [PubMed]

6. Gyebi, L.; Soltani, Z.; Reisin, E. Lipid nephrotoxicity: New concept for an old disease. Curr. Hypertens. Rep. 2012, 14, 177-181. [CrossRef]

7. Ruan, X.Z.; Varghese, Z.; Moorhead, J.F. An update on the lipid nephrotoxicity hypothesis. Nat. Rev. Nephrol. 2009, 5, 713-721. [CrossRef]

8. Liu, Y.; Wang, Z.; Yin, W.; Li, Q.; Cai, M.; Zhang, C.; Xiao, J.; Hou, H.; Li, H.; Zu, X. Severe insulin resistance and moderate glomerulosclerosis in a minipig model induced by high-fat/high-sucrose/high-cholesterol diet. Exp. Anim. 2007, 56, 11-20. [CrossRef]

9. Barakat, L.A.; Mahmoud, R.H. The antiatherogenic, renal protective and immunomodulatory effects of purslane, pumpkin and flax seeds on hypercholesterolemic rats. N. Am. J. Med. Sci. 2011, 3, 411-417. [CrossRef]

10. Pang, M.; Fang, Y.; Chen, S.; Zhu, X.; Shan, C.; Su, J.; Yu, J.; Li, B.; Yang, Y.; Chen, B. Gypenosides Inhibits Xanthine Oxidoreductase and Ameliorates Urate Excretion in Hyperuricemic Rats Induced by High Cholesterol and High Fat Food (Lipid Emulsion). Med. Sci. Monit. Int. Med. J. Exp. Clin. Res. 2017, 23, 1129-1140. [CrossRef]

11. Cases, A.; Coll, E. Dyslipidemia and the progression of renal disease in chronic renal failure patients. Kidney Int. 2005, 68, S87-S93. [CrossRef] [PubMed]

12. Madkor, H.R.; Mansour, S.W.; Ramadan, G. Modulatory effects of garlic, ginger, turmeric and their mixture on hyperglycaemia, dyslipidaemia and oxidative stress in streptozotocin-nicotinamide diabetic rats. Br. J. Nutr. 2011, 105, 1210-1217. [CrossRef] [PubMed]

13. Amagase, H. Clarifying the real bioactive constituents of garlic. J. Nutr. 2006, 136, 716S-725S. [CrossRef] [PubMed]

14. Kumar Gupta, S.; Sharma, A. Medicinal properties of Zingiber officinale Roscoe-A review. J. Pharm. Biol. Sci. 2014, 9, 124-129.

15. Afshari, A.T.; Shirpoor, A.; Farshid, A.; Saadatian, R.; Rasmi, Y.; Saboory, E.; Ilkhanizadeh, B.; Allameh, A. The effect of ginger on diabetic nephropathy, plasma antioxidant capacity and lipid peroxidation in rats. Food Chem. 2007, 101, 148-153. [CrossRef] 
16. Abdel-Azeem, A.S.; Hegazy, A.M.; Ibrahim, K.S.; Farrag, A.R.; El-Sayed, E.M. Hepatoprotective, antioxidant, and ameliorative effects of ginger (Zingiber officinale Roscoe) and vitamin $\mathrm{E}$ in acetaminophen treated rats. J. Diet. Suppl. 2013, 10, 195-209. [CrossRef] [PubMed]

17. Akhani, S.P.; Vishwakarma, S.L.; Goyal, R.K. Anti-diabetic activity of Zingiber officinale in streptozotocin-induced type I diabetic rats. J. Pharm. Pharmacol. 2004, 56, 101-105. [CrossRef]

18. ElRokh, E.-S.M.; Yassin, N.A.; El-Shenawy, S.M.; Ibrahim, B.M. Antihypercholesterolaemic effect of ginger rhizome (Zingiber officinale) in rats. Inflammopharmacology 2010, 18, 309-315. [CrossRef]

19. Ide, N.; Matsuura, H.; Itakura, Y. Scavenging effect of aged garlic extract and its constituents on active oxygen species. Phytother. Res. 1996, 10, 340-341. [CrossRef]

20. Kleijnen, J.; Knipschild, P.; Ter Riet, G. Garlic, onions and cardiovascular risk factors. A review of the evidence from human experiments with emphasis on commercially available preparations [see comments]. Br. J. Clin. Pharmacol. 1989, 28, 535-544. [CrossRef]

21. Pedraza-Chaverrí, J.; Maldonado, P.D.; Barrera, D.; Cerón, A.; Medina-Campos, O.N.; Pando, R.H. Protective effect of diallyl sulfide on oxidative stress and nephrotoxicity induced by gentamicin in rats. Mol. Cell. Biochem. 2003, 254, 125-130. [CrossRef] [PubMed]

22. Nakagawat, S.; Kasuga, S.; Matsuura, H. Prevention of liver damage by aged garlic extract and its components in mice. Phytother. Res. 1989, 3, 50-53. [CrossRef]

23. Bianchi, S.; Bigazzi, R.; Caiazza, A.; Campese, V.M. A controlled, prospective study of the effects of atorvastatin on proteinuria and progression of kidney disease. Am. J. Kidney Dis. 2003, 41, 565-570. [CrossRef] [PubMed]

24. Rabelink, A.; Erkelens, D.; Hene, R.; Joles, J.; Koomans, H. Effects of simvastatin and cholestyramine on lipoprotein profile in hyperlipidaemia of nephrotic syndrome. Lancet 1988, 332, 1335-1338. [CrossRef]

25. O’Donnell, M.P.; Kasiske, B.L.; Katz, S.A.; Schmitz, P.G.; Keane, W.F. Lovastatin but not enalapril reduces glomerular injury in Dahl salt-sensitive rats. Hypertension 1992, 20, 651-658. [CrossRef] [PubMed]

26. Chen, C.-H.; Yang, J.-C.; Uang, Y.-S.; Lin, C.-J. Improved dissolution rate and oral bioavailability of lovastatin in red yeast rice products. Int. J. Pharm. 2013, 444, 18-24. [CrossRef] [PubMed]

27. Tobert, J.; Hitzenberger, G.; Kukovetz, W.; Holmes, I.; Jones, K. Rapid and substantial lowering of human serum cholesterol by mevinolin (MK-803), an inhibitor of hydroxymethylglutaryl-coenzyme A reductase. Atherosclerosis 1982, 41, 61-65. [CrossRef]

28. Shattat, G.F. A review article on hyperlipidemia: Types, treatments and new drug targets. Biomed. Pharmacol. J. 2015, 7, 399-409. [CrossRef]

29. Vega, G.L.; Grundy, S.M. Lovastatin therapy in nephrotic hyperlipidemia: Effects on lipoprotein metabolism. Kidney Int. 1988, 33, 1160-1168. [CrossRef]

30. Meng, F.F.; Asghar, S.; Gao, S.Y.; Su, Z.G.; Song, J.; Huo, M.R.; Meng, W.D.; Ping, Q.N.; Xiao, Y.Y. A novel LDL-mimic nanocarrier for the targeted delivery of curcumin into the brain to treat Alzheimer's disease. Colloid Surf. B 2015, 134, 88-97. [CrossRef]

31. Chien, M.-Y.; Ku, Y.-H.; Chang, J.-M.; Yang, C.-M.; Chen, C.-H. Effects of herbal mixture extracts on obesity in rats fed a high-fat diet. J. Food Drug Anal. 2016, 24, 594-601. [CrossRef] [PubMed]

32. Shukr, M.H.; Ismail, S.; Ahmed, S.M. Development and optimization of ezetimibe nanoparticles with improved antihyperlipidemic activity. J. Drug Deliv. Sci. Technol. 2019, 49, 383-395. [CrossRef]

33. Behiry, E.G.; El Nady, N.M.; AbdEl Haie, O.M.; Mattar, M.K.; Magdy, A. Evaluation of TG-HDL Ratio Instead of HOMA Ratio as Insulin Resistance Marker in Overweight and Children with Obesity. Endocr. Metab. Immune Disord. Drug Targets 2019, 19, 676-682. [CrossRef] [PubMed]

34. Farahat, A.; Salem, H.; Abass, H.; Elmosalamy, S.; Hassan, N. Favourable Lipid Modulatory and Renal Protective Effects of Ginger and Fish Oil in Hypercholesterolemic Male Rats. Vet. Med. J. 2017, 63, $33-45$.

35. Shiju, T.; Rajesh, N.; Viswanathan, P. Renoprotective effect of aged garlic extract in streptozotocin-induced diabetic rats. Indian J. Pharmacol. 2013, 45, 18-23. [CrossRef] [PubMed]

36. Iwani, N.A.K.Z.; Jalaludin, M.Y.; Zin, R.M.W.M.; Fuziah, M.Z.; Hong, J.Y.H.; Abqariyah, Y.; Mokhtar, A.H.; Nazaimoon, W.M.W. Triglyceride to HDL-C ratio is associated with insulin resistance in overweight and obese children. Sci. Rep. 2017, 7, 40055. [CrossRef] [PubMed]

37. Bolanle, A.O. Effect of ginger powder (Zingiber officinale) on plasma lipid profile and liver enzyme activities of hypercholesterolemic rats. J. Life Sci. 2011, 5, 712-716. 
38. You, H.; Hao, R.; Li, R.; Zhang, L.; Zhu, Y.; Luo, Y. The effect of radish sourced 4-(methylthio)-3-butenyl isothiocyanate on ameliorating the severity of high fat diet inducted nonalcoholic fatty liver disease in rats. Int. J. Clin. Exp. Med. 2015, 8, 15910-15919.

39. Liu, I.M.; Tzeng, T.F.; Liou, S.S.; Chang, C.J. Regulation of obesity and lipid disorders by extracts from Angelica acutiloba root in high-fat diet-induced obese rats. Phytother. Res. 2012, 26, 223-230. [CrossRef]

40. Björntorp, P.; Sjöström, L. Number and size of adipose tissue fat cells in relation to metabolism in human obesity. Metabolism 1971, 20, 703-713. [CrossRef]

41. Iwasaki, Y.; Morita, A.; Iwasawa, T.; Kobata, K.; Sekiwa, Y.; Morimitsu, Y.; Kubota, K.; Watanabe, T. A nonpungent component of steamed ginger-[10]-shogaol—increases adrenaline secretion via the activation of TRPV1. Nutr. Neurosci. 2006, 9, 169-178. [PubMed]

42. Mahmoud, R.; Elnour, W. Comparative evaluation of the efficacy of ginger and orlistat on obesity management, pancreatic lipase and liver peroxisomal catalase enzyme in male albino rats. Eur. Rev. Med. Pharmacol. Sci. 2013, 17, 75-83. [PubMed]

43. Lai, Y.-S.; Chen, W.-C.; Ho, C.-T.; Lu, K.-H.; Lin, S.-H.; Tseng, H.-C.; Lin, S.-Y.; Sheen, L.-Y. Garlic essential oil protects against obesity-triggered nonalcoholic fatty liver disease through modulation of lipid metabolism and oxidative stress. J. Agric. Food Chem. 2014, 62, 5897-5906. [CrossRef] [PubMed]

44. Shin, S.K.; Ha, T.Y.; McGregor, R.A.; Choi, M.S. Long-term curcumin administration protects against atherosclerosis via hepatic regulation of lipoprotein cholesterol metabolism. Mol. Nutr. Food Res. 2011, 55, 1829-1840. [CrossRef] [PubMed]

45. Gill, B.; Singh, J.; Sharma, V.; Kumar, S.H. Emulsomes: An emerging vesicular drug delivery system. Asian J. Pharm. 2012, 6, 87-94. [CrossRef]

46. Saravanan, G.; Ponmurugan, P.; Deepa, M.A.; Senthilkumar, B. Anti-obesity action of gingerol: Effect on lipid profile, insulin, leptin, amylase and lipase in male obese rats induced by a high-fat diet. J. Sci. Food Agric. 2014, 94, 2972-2977. [CrossRef] [PubMed]

47. Sharma, P.K.; Singh, V.; Ali, M. Chemical composition and antimicrobial activity of fresh rhizome essential oil of Zingiber officinale Roscoe. Pharmacogn. J. 2016, 8, 185-190. [CrossRef]

48. Al-Noory, A.S.; Amreen, A.-N.; Hymoor, S. Antihyperlipidemic effects of ginger extracts in alloxan-induced diabetes and propylthiouracil-induced hypothyroidism in (rats). Pharmacogn. Res. 2013, 5, 157-161.

49. Choi, S.-Y.; Park, G.-S.; Lee, S.Y.; Kim, J.Y.; Kim, Y.K. The conformation and CETP inhibitory activity of [10]-dehydrogingerdione isolated from Zingiber officinale. Arch. Pharmacal Res. 2011, 34, 727-731. [CrossRef] [PubMed]

50. Elseweidy, M.M.; Abdallah, F.R.; Younis, N.N.; Aldohmy, S.; Kassem, H.M. 10-Dehydrogingerdione raises HDL-cholesterol through a CETP inhibition and wards off oxidation and inflammation in dyslipidemic rabbits. Atherosclerosis 2013, 231, 334-340. [CrossRef]

51. Paul, P.; Islam, M.; Mustari, A.; Khan, M. Hypolipidemic effect of ginger extract in vanaspati fed rats. Bangladesh J. Vet. Med. 2012, 10, 93-96. [CrossRef]

52. Elseweidy, M.; Younis, N.; Elswefy, S.; Abdallah, F.; El-Dahmy, S.; Elnagar, G.; Kassem, H. Atheroprotective potentials of curcuminoids against ginger extract in hypercholesterolaemic rabbits. Nat. Prod. Res. 2015, 29, 961-965. [CrossRef] [PubMed]

53. Lee, Y.-M.; Gweon, O.-C.; Seo, Y.-J.; Im, J.; Kang, M.-J.; Kim, M.-J.; Kim, J.-I. Antioxidant effect of garlic and aged black garlic in animal model of type 2 diabetes mellitus. Nutr. Res. Pract. 2009, 3, 156-161. [CrossRef] [PubMed]

54. Anwar, M.M.; Meki, A.-R.M. Oxidative stress in streptozotocin-induced diabetic rats: Effects of garlic oil and melatonin. Comp. Biochem. Physiol. Part. A Mol. Integr. Physiol. 2003, 135, 539-547. [CrossRef]

55. Mikaili, P.; Maadirad, S.; Moloudizargari, M.; Aghajanshakeri, S.; Sarahroodi, S. Therapeutic Uses and Pharmacological Properties of Garlic, Shallot, and Their Biologically Active Compounds. Iran. J. Basic Med. Sci. 2013, 16, 1031-1048. [PubMed]

56. Park, E.Y.; Ki, S.H.; Ko, M.S.; Kim, C.W.; Lee, M.H.; Lee, Y.S.; Kim, S.G. Garlic oil and DDB, comprised in a pharmaceutical composition for the treatment of patients with viral hepatitis, prevents acute liver injuries potentiated by glutathione deficiency in rats. Chem. Biol. Interact. 2005, 155, 82-96. [CrossRef] [PubMed]

57. Kwon, M.-J.; Song, Y.-S.; Choi, M.-S.; Park, S.-J.; Jeong, K.-S.; Song, Y.-O. Cholesteryl ester transfer protein activity and atherogenic parameters in rabbits supplemented with cholesterol and garlic powder. Life Sci. 2003, 72, 2953-2964. [CrossRef] 
58. Yeh, Y.-Y.; Liu, L. Cholesterol-lowering effect of garlic extracts and organosulfur compounds: Human and animal studies. J. Nutr. 2001, 131, 989S-993S. [CrossRef]

59. Banerjee, S.K.; Maulik, S.K. Effect of garlic on cardiovascular disorders: A review. Nutr. J. $2002,1,4$. [CrossRef]

60. Bo, M.S.; Cheah, W.L.; Lwin, S.; Moe Nwe, T.; Win, T.T.; Aung, M. Understanding the relationship between atherogenic index of plasma and cardiovascular disease risk factors among staff of an University in Malaysia. J. Nutr. Metab. 2018. [CrossRef]

61. Ginsberg, H.N. Efficacy and mechanisms of action of statins in the treatment of diabetic dyslipidemia. J. Clin. Endocrinol. Metab. 2006, 91, 383-392. [CrossRef] [PubMed]

62. Khandouzi, N.; Shidfar, F.; Rajab, A.; Rahideh, T.; Hosseini, P.; Taheri, M.M. The effects of ginger on fasting blood sugar, hemoglobin a1c, apolipoprotein B, apolipoprotein aI and malondialdehyde in type 2 diabetic patients. Iran. J. Pharm. Res. 2015, 14, 131-140. [PubMed]

63. Atkin, M.; Laight, D.; Cummings, M.H. The effects of garlic extract upon endothelial function, vascular inflammation, oxidative stress and insulin resistance in adults with type 2 diabetes at high cardiovascular risk. A pilot double blind randomized placebo controlled trial. J. Diabetes Complicat. 2016, 30, 723-727. [CrossRef] [PubMed]

64. Wright, P.; Leathwood, P.; Plummer, D. Enzymes in rat urine: Alkaline phosphatase. Enzymologia 1972, 42, 317-327. [PubMed]

65. Christen, P.; Metzler, D. Aminotransferases; Wiley Interscience Inc.: New York, NY, USA, 1985.

66. Prades, J.; Funari, S.S.; Escribá, P.V.; Barceló, F. Effects of unsaturated fatty acids and triacylglycerols on phosphatidylethanolamine membrane structure. J. Lipid Res. 2003, 44, 1720-1727. [CrossRef] [PubMed]

67. Sakr, S.A.; Mahran, H.A.; Lamfon, H.A. Protective effect of ginger (Zingiber officinale) on adriamycin-induced hepatotoxicity in albino rats. J. Med. Plants Res. 2011, 5, 133-140.

68. Ahmed, R.S.; Seth, V.; Banerjee, B.D. Influence of dietary ginger (Zingiber officinales Rosc) on antioxidant defense system in rat: Comparison with ascorbic acid. Indian J. Exp. Biol. 2000, 38, 604-606.

69. Motawi, T.K.; Hamed, M.A.; Shabana, M.H.; Hashem, R.M.; Naser, A.F.A. Zingiber officinale acts as a nutraceutical agent against liver fibrosis. Nutr. Metab. 2011, 8, 40. [CrossRef]

70. Eissa, F.A.; Choudhry, H.; Abdulaal, W.H.; Baothman, O.A.; Zeyadi, M.; Moselhy, S.S.; Zamzami, M.A. Possible hypocholesterolemic effect of ginger and rosemary oils in rats. Afr. J. Tradit. Complement. Altern. Med. 2017, 14, 188-200. [CrossRef]

71. Rahimlou, M.; Yari, Z.; Hekmatdoost, A.; Alavian, S.M.; Keshavarz, S.A. Ginger supplementation in nonalcoholic fatty liver disease: A randomized, double-blind, placebo-controlled pilot study. Hepat. Mon. 2016, 16, e34897. [CrossRef]

72. Heeba, G.H.; Abd-Elghany, M.I. Effect of combined administration of ginger (Zingiber officinale Roscoe) and atorvastatin on the liver of rats. Phytomedicine 2010, 17, 1076-1081. [CrossRef] [PubMed]

73. Shaarawy, S.M.; Tohamy, A.A.; Elgendy, S.M.; Elmageed, Z.Y.A.; Bahnasy, A.; Mohamed, M.S.; Kandil, E.; Matrougui, K. Protective effects of garlic and silymarin on NDEA-induced rats hepatotoxicity. Int. J. Biol. Sci. 2009, 5, 549-557. [CrossRef] [PubMed]

74. Kim, N.D.; Kwak, M.K.; Kim, S.G. Inhibition of cytochrome P450 2E1 expression by 2-(allylthio) pyrazine, a potential chemoprotective agent: Hepatoprotective effects. Biochem. Pharmacol. 1997, 53, 261-269. [CrossRef]

75. Aguila, M.B.; Mandarim-De-Lacerda, C.A. Effects of chronic high fat diets on renal function and cortical structure in rats. Exp. Toxicol. Pathol. 2003, 55, 187-195. [CrossRef] [PubMed]

76. Altunkaynak, M.E.; Ozbek, E.; Altunkaynak, B.Z.; Can, I.; Unal, D.; Unal, B. The effects of high-fat diet on the renal structure and morphometric parametric of kidneys in rats. J. Anat. 2008, 212, 845-852. [CrossRef] [PubMed]

77. Popov, D.; Simionescu, M.; Shepherd, P. Saturated-fat diet induces moderate diabetes and severe glomerulosclerosis in hamsters. Diabetologia 2003, 46, 1408-1418. [CrossRef] [PubMed]

78. Ravid, M.; Brosh, D.; Ravid-Safran, D.; Levy, Z.; Rachmani, R. Main risk factors for nephropathy in type 2 diabetes mellitus are plasma cholesterol levels, mean blood pressure, and hyperglycemia. Arch. Intern. Med. 1998, 158, 998-1004. [CrossRef]

79. Khan, M.R.; Rizvi, W.; Khan, G.N.; Khan, R.A.; Shaheen, S. Carbon tetrachloride-induced nephrotoxicity in rats: Protective role of Digera muricata. J. Ethnopharmacol. 2009, 122, 91-99. [CrossRef] 
80. Khan, R.A.; Khan, M.R.; Sahreen, S.; Bokhari, J. Prevention of CCl4-induced nephrotoxicity with Sonchus asper in rat. Food Chem. Toxicol. 2010, 48, 2469-2476. [CrossRef]

81. Elshater, A.; Salman, M.M.; Moussa, M.M. Effect of ginger extract consumption on levels of blood glucose, lipid profile and kidney functions in alloxan induced-diabetic rats. Egypt. Acad. J. Biol. Sci. 2009, 2, 153-162. [CrossRef]

82. Lebda, M.A.; Taha, N.M.; Korshom, M.A.; Mandour, A.E.A.; El-Morshedy, A.M. Biochemical effect of ginger on some blood and liver parameters in male New Zealand rabbits. Online J. Anim. Feed Res. 2012, 2, 197-202.

83. Mehrdad, M.; Messripour, M.; Ghobadipour, M. The effect of ginger extract on blood urea nitrogen and creatinine in mice. Pak. J. Biol. Sci. 2007, 10, 2968-2971. [PubMed]

84. Rodrigues, F.A.; Prata, M.M.; Oliveira, I.C.; Alves, N.T.; Freitas, R.E.; Monteiro, H.S.; Vieira, P.C.; Viana, D.A.; Libório, A.B.; Havt, A. Gingerol fraction from Zingiber officinale protects against gentamicin-induced nephrotoxicity. Antimicrob. Agents Chemother. 2014, 58, 1872-1878. [CrossRef] [PubMed]

85. Kazemipour, N.; Moradi, S.; Sepehrimanesh, M.; Nazifi, S. Evaluation of the effects of alcoholic extract of ginger on renal cytotoxicity of silver nanoparticles: A Mus musculus model. Comp. Clin. Pathol. 2018, 27, 1587-1593. [CrossRef]

86. Harris, K.P.; Purkerson, M.L.; Yates, J.; Klahr, S. Lovastatin ameliorates the development of glomerulosclerosis and uremia in experimental nephrotic syndrome. Am. J. Kidney Dis. 1990, 15, 16-23. [CrossRef]

87. Oda, H.; Keane, W.F. Recent advances in statins and the kidney. Kidney Int. 1999, 56, S2-S5. [CrossRef]

88. Buemi, M.; Allegra, A.; Corica, F.; Aloisi, C.; Giacobbe, M.; Pettinato, G.; Corsonello, A.; Senatore, M.; Frisina, N. Effect of fluvastatin on proteinuria in patients with immunoglobulin A nephropathy. Clin. Pharmacol. Ther. 2000, 67, 427-431. [CrossRef] [PubMed]

89. Gulnaz, H.; Tahir, M.; Munir, B.; Sami, W.J.B. Protective effects of garlic oil on acetaminophen induced nephrotoxicity in male albino rats. Biomedica 2010, 26, 9-15.

90. Kabasakal, L.; Şehirli, Ö.; Çetinel, Ş.; Cikler, E.; Gedik, N.; Şener, G. Protective effect of aqueous garlic extract against renal ischemia/reperfusion injury in rats. J. Med. Food 2005, 8, 319-326. [CrossRef]

91. Pedraza-Chaverrí, J.; Maldonado, P.D.; Medina-Campos, O.N.; Olivares-Corichi, I.M.; de los Ángeles Granados-Silvestre, M.; Hernández-Pando, R.; Ibarra-Rubio, M.E. Garlic ameliorates gentamicin nephrotoxicity: Relation to antioxidant enzymes. Free Radic. Biol. Med. 2000, 29, 602-611. [CrossRef]

92. Adams, L.A.; Lymp, J.F.; St Sauver, J.; Sanderson, S.O.; Lindor, K.D.; Feldstein, A.; Angulo, P. The natural history of nonalcoholic fatty liver disease: A population-based cohort study. Gastroenterology 2005, 129, 113-121. [CrossRef] [PubMed]

93. Zafrani, E.S. Non-alcoholic fatty liver disease: An emerging pathological spectrum. Virchows Arch. 2004, 444, 3-12. [CrossRef] [PubMed]

94. Hamaguchi, M.; Kojima, T.; Takeda, N.; Nakagawa, T.; Taniguchi, H.; Fujii, K.; Omatsu, T.; Nakajima, T.; Sarui, H.; Shimazaki, M. The metabolic syndrome as a predictor of nonalcoholic fatty liver disease. Ann. Intern. Med. 2005, 143, 722-728. [CrossRef] [PubMed]

95. Reddy, J.K.; Sambasiva Rao, M. Lipid metabolism and liver inflammation. II. Fatty liver disease and fatty acid oxidation. Am. J. Physiol. Gastrointest. Liver Physiol. 2006, 290, G852-G858. [CrossRef] [PubMed]

96. Kume, S.; Uzu, T.; Araki, S.-I.; Sugimoto, T.; Isshiki, K.; Chin-Kanasaki, M.; Sakaguchi, M.; Kubota, N.; Terauchi, Y.; Kadowaki, T. Role of altered renal lipid metabolism in the development of renal injury induced by a high-fat diet. J. Am. Soc. Nephrol. 2007, 18, 2715-2723. [CrossRef] [PubMed]

97. Hamed, M.A.; Ali, S.A.; Saba El-Rigal, N. Therapeutic potential of ginger against renal injury induced by carbon tetrachloride in rats. Sci. World J. 2012. [CrossRef] [PubMed]

98. Pedraza-Chaverri, J.; Medina-Campos, O.; de los Angeles Granados-Silvestre, M.; Maldonado, P.; Olivares-Corichi, I.; Hernández-Pando, R. Garlic ameliorates hyperlipidemia in chronic aminonucleoside nephrosis. Mol. Cell. Biochem. 2000, 211, 69-77. [CrossRef]

99. Aviello, G.; Abenavoli, L.; Borrelli, F.; Capasso, R.; Izzo, A.A.; Lembo, F.; Romano, B.; Capasso, F. Garlic: Empiricism or science? Nat. Prod. Commun. 2009, 4, 1785-1796. [CrossRef]

(C) 2019 by the authors. Licensee MDPI, Basel, Switzerland. This article is an open access article distributed under the terms and conditions of the Creative Commons Attribution (CC BY) license (http://creativecommons.org/licenses/by/4.0/). 